\title{
Effects of Porosity and Water Saturation on the Yield Surface of Upper Cretaceous Reservoir Chalks From the Danish North Sea
}

Amour, F.; Christensen, H. F.; Hajiabadi, M.R.; Nick, H.M.

Published in:

Journal of Geophysical Research: Solid Earth

Link to article, DOI:

10.1029/2020JB020608

Publication date:

2021

Document Version

Peer reviewed version

Link back to DTU Orbit

Citation (APA):

Amour, F., Christensen, H. F., Hajiabadi, M. R., \& Nick, H. M. (2021). Effects of Porosity and Water Saturation on the Yield Surface of Upper Cretaceous Reservoir Chalks From the Danish North Sea. Journal of Geophysical Research: Solid Earth, 126(3), [e2020JB020608]. https://doi.org/10.1029/2020JB020608

\section{General rights}

Copyright and moral rights for the publications made accessible in the public portal are retained by the authors and/or other copyright owners and it is a condition of accessing publications that users recognise and abide by the legal requirements associated with these rights.

- Users may download and print one copy of any publication from the public portal for the purpose of private study or research.

- You may not further distribute the material or use it for any profit-making activity or commercial gain

- You may freely distribute the URL identifying the publication in the public portal 


\title{
Effects of porosity and water saturation on the yield surface of Upper Cretaceous reservoir chalks from the Danish North Sea
}

\author{
F. Amour ${ }^{1}$, H. F. Christensen ${ }^{2}$, M. R. Hajiabadi ${ }^{1}$, H. M. Nick ${ }^{1}$ \\ ${ }^{1}$ Danish Hydrocarbon Research and Technology Centre/Technical University of Denmark, \\ Lyngby, Denmark. \\ ${ }^{2}$ GEO, Lyngby, Denmark
}

Corresponding author: Frédéric Amour (amour@dtu.dk)

\section{Key Points}

- Yield surface of $30 \%$ to $45 \%$ porosity chalk at $0 \%$ and $100 \%$ water saturation is reconstructed in plots of mean-deviatoric stress vs. porosity.

- Yield functions considering the water weakening effect are proposed to model a wide spectrum of compacting clean chalks.

- Key mechanical properties of the North Sea chalk for compaction studies. 


\begin{abstract}
The locus and shape of the yield surface of chalk in the stress space represent key input parameters in geomechanical models, as it dictates the onset and amount of plastic deformation. The study aims at reconstructing for the first time the initial end cap and shear failure line of intact reservoir chalk in plots of mean-deviatoric stress vs. porosity. 137 stress-strain measurements describe the effects of initial porosity between $30 \%$ and $45 \%$ and initial water saturation on the yield surface in order to cover a wide spectrum of reservoir rocks. The physico-chemical processes taking place at pore collapse under oil- and water-saturated conditions are discussed. The experimental data collected from previous works quantify the hardening and softening effects observed with decreasing porosity and increasing water saturation. The results also indicate that the stress interval characterising the elastic to elastoplastic transition zone and the curvature of the end cap are dependent on porosity and quartz content. These observed trends suggest changes in the sequence of local failures acting in the rock matrix at the onset of compaction. Comparisons with previous studies suggest that the water weakening effect differs between outcrop and reservoir chalk likely due to a change in mineralogy. A yield function is proposed to build the yield surface and to capture the porositydependent change in the shape of end cap and the water weakening effect. The outcomes provide key input data describing the mechanical behaviour and properties of chalk under laboratory conditions required for compaction simulation studies.
\end{abstract}

\title{
1 Introduction
}

The exploitation of a hydrocarbon field causes in situ changes in the stress state, pore pressure and rock-fluid interactions, which in turn modify the petrographic, petrophysical and geomechanics properties of reservoir rocks (Goulty, 2003; Heggheim et al., 2005; KågesonLoe et al., 1993; Risnes et al., 2005; Ruddy et al., 1989; de Waal, 1986). One of the most known and studied consequences of these in situ changes is the compaction of chalk reservoirs in the North Sea, first observed in the Ekofisk field and associated with almost $4 \mathrm{~m}$ seafloor subsidence (Boade et al., 1989). Wellbore instability and fault reactivation are two additional consequences of reservoir, sideburden and overburden deformation that can jeopardise the integrity of oil and gas infrastructures and, ultimately, the economic viability of fields (Schutjens et al., 2018). Besides, the efficiency of stimulation methods such as radial jet drilling and the interpretation of time-lapse seismic are dependent on changes in mechanical properties associated with compaction (Angus et al., 2015; Medetbekova et al., 2020). The physical and chemical processes controlling the mechanical behaviour of chalk have been studied to assess

This article is protected by copyright. All rights reserved. 
and mitigate risks associated with hydrocarbon production (e.g. Andersen et al., 1992; Havmøller \& Foged, 1996; Hickman, 2004; Leddra, 1989).

When a rock is subject to an increasing stress, linear behaviour assumed as elastic and reversible is first observed. And, if the stress path reaches a threshold, so-called the rock strength, the rock fails in one of the three conceptual failure modes, tensile and shear failures and pore collapse. The $\mathrm{p}_{\mathrm{m}}^{\prime} \mathrm{q}$ plot displays the mean effective stress $\mathrm{p}_{\mathrm{m}}^{\prime}$, which refers to the mean stress $p_{m}=\left(\sigma_{1}+\sigma_{2}+\sigma_{3}\right) / 3$ minus pore pressure, on the $x$-axis and the deviatoric stress $q=$ $\sqrt{1 / 2\left(\left(\sigma_{1}-\sigma_{2}\right)^{2}+\left(\sigma_{2}-\sigma_{3}\right)^{2}+\left(\sigma_{3}-\sigma_{1}\right)^{2}\right)}$ on the y-axis where $\sigma_{1}, \sigma_{2}$ and $\sigma_{3}$ denotes principal stresses. In standard triaxial test, $q=\sigma_{1}-\sigma_{3}$. The plot represents a useful 2dimensional graphical illustration of the admissible stress space and the stress regime applied to rocks. Multiple stress paths can be applied to rocks until failure or pore collapse, and the corresponding strength can be plotted into a p plot. The concept of yield surface implies that all the failure and pore collapse points form a line in the $\mathrm{p}_{\mathrm{m}}^{\prime} \mathrm{q}$ plot that separates the elastic and inelastic deformation. The yield surface is composed of two connecting surfaces, the shear failure line and the end cap (Figure 1). The shear failure line is based on the Mohr-Coulomb criterion, the rock cohesion, $S_{0}$, and the friction angle, $\varphi$ (Mohr, 1900). The shear failure occurs when the Mohr circle hits the failure line, i.e. when the difference between the principal stresses is large enough to generate shear stress reaching the shear strength of rock. The tensile strength $T_{0}$ can also be plotted in the extension regime, i.e. when stress is negative, and corresponds to the maximum extensive stress withstands by the rock before failure. Tensile and shear failures are irreversible deformations localised along few tensile and shear fractures, respectively.

The end cap defines the yield stress $\left(\sigma_{\mathrm{y}}\right)$ at which pore collapse occurs during the transition between the assumed elastic to elasto-plastic regime. The end cap is represented by an ellipse closing the yield surface at high $\mathrm{p}_{\mathrm{m}}^{\prime}$. The value of $\sigma_{\mathrm{y}}$ measured under hydrostatic conditions corresponds to the hydrostatic yield stress noted by $\sigma_{\text {hy }}$ (Figure 1). Pore collapse is a non-linear, irreversible plastic deformation distributed uniformly throughout the rock under high confining stress. During pore collapse, contact cements between individual calcite grains break or, at least, weaken enough to cause grain-to-grain slip that leads to a tighter packing of porous material by grain re-arrangement and crushing and collapse of pores (Fabricius, 2007). Andersen (1995) has introduced the concept of failure nucleus to illustrate the propagation of local failures throughout the rock fabric. During pore collapse, local failures of pore walls and contact cements induce a new stress redistribution within the solid skeleton. A cascade of failure-stress redistributions is thus triggered causing additional local failures. Changes in pore

This article is protected by copyright. All rights reserved. 
collapse mechanisms with porosity were indirectly observed by monitoring the permeability of chalk specimens tested under uniaxial compaction conditions (Leddra, 1989). An abrupt decline in axial permeability parallel to $\sigma_{1}$ and perpendicular to bedding was measured at pore collapse in highly porous specimens up to $41.5 \%$ porosity. Contrarily, less porous chalks show a permeability enhancement interpreted as the result of micro-crack formation caused by local pore collapses. Furthermore, the onset of pore collapse is sensitive to the amount of applied deviatoric stress. Shear stress is thought to promote the mechanical instability of the weakest areas in the rock matrix such as large pores and their subsequent collapses (Curran \& Carroll, 1979; Kågeson-Loe et al., 1993; Vajdova et al., 2012).

In order to predict the onset of plastic deformation in a producing field, compaction modelling studies rely on accurate estimations of rock mechanical properties including the locus and shape of end cap in the stress space. Considering clean chalk lithology with a negligible amount of clay and quartz, the yield surface is not static and changes locus depending on four key parameters: porosity, saturating fluid, temperature and rate of deformation. Triaxial tests on intact chalk specimens demonstrated the expansion (i.e. hardening) of the yield surface with decreasing porosity and higher rate of deformation, and its shrinkage (i.e. softening) with increasing water saturation $\left(\mathrm{S}_{\mathrm{w}}\right)$ and temperature (M. A. Andersen et al., 1992; P. Ø. Andersen et al., 2018; Collin et al., 2002; Havmøller \& Foged, 1996; Hickman, 2004; Homand \& Shao, 2000; Johnsen et al., 2011; Korsnes et al., 2008; Megawati et al., 2013; Minde et al., 2018; Papamichos et al., 1997; Risnes et al., 1998, 2005; Risnes \& Flaageng, 1999; Schroeder et al., 1998). The large majority of previous studies were conducted on outcrop chalk, thereby limiting applicability of the results to the deep subsurface chalks. Besides, the reconstruction of initial end caps in $p_{m}^{\prime}-q$ plot was carried out by quantifying the evolution of $\sigma_{\text {hy }}$ with porosity. The end caps were commonly assumed as parallel surfaces which expand and shrink depending on the chalk porosity. This approach is helpful when dealing with a limiting amount of experimental data.

The present study aims to reconstruct the end cap and shear failure line of intact pelagic chalk in $p_{m}^{\prime}-q$ plot as a function of porosity using experimental data carried out on reservoir specimens. The total of 85 geomechanical tests previously performed between 1989 and 2007 and compiled in JCR database (http://jointchalkresearch.org/) are selected to use in this study. 137 stress-strain measurements on $30 \%$ to $45 \%$ porosity and $0 \%, 20 \%$ and $100 \%$ watersaturated specimens are collected and used to cover a wide spectrum of chalk reservoir types that are likely to deform elasto-plastically in a producing field. Specific attention is paid to the

This article is protected by copyright. All rights reserved. 
evolution of the end cap as functions of initial porosity and initial $S_{\mathrm{w}}$. To this end, experimental data from hydrostatic compaction, uniaxial strain compaction and shear failure tests are grouped into six porosity classes. For each porosity class, the data are plotted into $\mathrm{p}_{\mathrm{m}}^{\prime} \mathrm{q}$ plot in order to characterise the locus and shape of each yield surface. Then, a yield function is used to reconstruct in a p p'-q-porosity plot the yield surface of oil- and water-saturated chalk with a porosity between $30 \%$ and $45 \%$.

\section{Background Knowledge}

\section{$2.1 \quad$ Yield stress $\left(\sigma_{\mathrm{y}}\right)$}

As the applied stress approaches $\sigma_{\mathrm{y}}$ (Figure 2a), the stress-strain curve deviates from the interpreted linear elastic trend and the slope $\Delta \sigma / \Delta \varepsilon$ reaches a lower value due to an added plastic component of the total strain (Smits et al., 1988). Although $\sigma_{\mathrm{y}}$ refers to a finite stress value delimiting the elastic and plastic regime, pore collapse does not happen abruptly at the given stresses. The elastic to elasto-plastic transition is better characterised by a range of stresses. Havmøller and Foged (1996) have proposed three different yield stresses to characterise the transition. The initial $\left(\sigma_{\mathrm{y}, \text { in. }}\right)$ and final yield stresses $\left(\sigma_{\mathrm{y}, \text { fin. }}\right)$ delimitate the transition zone and correspond to the first deviation of the stress-strain curve from the assumed linear elastic behaviour and the onset of linear plastic deformation, respectively. An intermediate yield stress, ranging between $\sigma_{y, \text { in. }}$ and $\sigma_{\mathrm{y}, \text { fin. }}$ and referred to as the pragmatic or typical yield stress, was proposed in the literature to approximate $\sigma_{\mathrm{y}}$ for a given specimen tested. The definition of this intermediate value varies among studies. For example, Havmøller and Foged (1996) have calculated the yield stress when the ratio $\Delta \sigma / \Delta \varepsilon$ in the elastic domain is reduced by $50 \%$. Nermoen et al. (2016) however, have assigned the yield stress value along the stress-strain curve that corresponds to the strain at which the interpolated linear elastic and plastic trends intercept.

\subsection{Controlling factors on the locus of yield surface}

The mechanical and chemical compaction of chalk during burial involves calcite recrystallisation and cementation processes, which bind individual calcite grains and reduce porosity, thereby forming a rigid rock fabric (Fabricius, 2003; Fabricius \& Borre, 1998; da Silva et al., 1985). Porosity reduction from $40 \%$ to $30 \%$ in water-saturated outcrop chalk leads to an exponential increase in $\sigma_{\text {hy }}$, i.e. a strengthening of the rock, from $9 \mathrm{MPa}$ to $30 \mathrm{MPa}$, respectively (Johnsen et al., 2011). During elasto-plastic deformation, rocks can withstand higher stresses beyond pore collapse indicating a strengthening mechanical behaviour under 
compaction (Risnes et al., 1998). This behaviour is known as the hardening effect and is thought to be resulted from grain re-arrangement and crushing that densify and strengthen rocks. Furthermore, the replacement of oil by water in pore space favours chalk softening (Heggheim et al., 2005; Schroeder et al., 1998; Zhang \& Spiers, 2005). This phenomenon is referred to as the water weakening effect. Experimental studies have shown a $42 \%$ to $65 \%$ decrease in $\sigma_{\text {hy }}$ from oil- to water-saturated conditions for outcrop chalks with a porosity ranging between 34\% and 45\% (Homand \& Shao, 2000; Papamichos et al., 1997; Risnes et al., 2005; Schroeder et al., 1998). The water weakening effect takes place at $S_{\mathrm{w}}$ between $0 \%$ and $20 \%$ and for the majority of the tested samples this occurs for $\mathrm{S}_{\mathrm{w}}<5 \%$ (Collin et al., 2002; Hickman, 2004; Schroeder et al., 1998; Talesnick \& Shehadeh, 2007). This mechanical weakening is an almost instantaneous phenomenon and the mechanisms are still debatable. It is suggested that chalk weakening is caused by adsorption of ions in the fluid (i.e. water) at the surface of calcite particles (Megawati et al., 2013; Risnes et al., 2005). An additional disjoining pressure induced by electrostatic repulsive forces between grains is exerted at intergranular contacts, counteracting adhesive forces and stimulating grain-to-grain slippage. Due to the low estimated values of the disjoining pressure, a repulsive hydration force created by hydration of highly hydrophilic calcite surfaces has been proposed as an alternative driven mechanism (Røyne et al., 2015). Capillarity pressure has also been identified as a potential controlling mechanism for the chalk water weakening (Delage et al., 1996; De Gennaro et al., 2004; De Gennaro \& Pereira, 2013; Ma et al., 2019; Taibi et al., 2009). At grain contacts, the water menisci that locally hold grains together are reduced as specimens are water flooded, resulting into the weakening of rock strength. The latter interpretation has been discarded by Risnes et al. (2005) that have observed water weakening effect on chalks saturated with two miscible fluids, water and glycol as substitutes for the two immiscible fluids present in reservoirs, brine and oil. Additional chemical processes such as $\mathrm{Ca}^{2+}$ substitution and calcite and quartz dissolution acting over a long period of time (typically few weeks to months) are considered to promote the water weakening in chalks (Heggheim et al., 2005; Korsnes et al., 2008; Loe et al., 1992; Minde et al., 2018). These chemical processes are enhanced at elevated temperature typically above $100^{\circ} \mathrm{C}$ (Nermoen et al., 2016). Another important aspect for compaction is the rate-dependency of rock mechanical behaviour (Andersen et al., 1992; Leddra, 1989; de Waal, 1986). At a given porosity value, chalk appears stronger when the applied stress or strain rate increases.

This article is protected by copyright. All rights reserved. 


\subsection{Yield function}

The yield function is the mathematical representation of the yield surface in stress space, such as the $p_{m}^{\prime}-q$ plots. The function estimates the locus of points in stress space at which plastic deformation initiates. Further deformation causes the stress state to remain on the yield surface, even though the shape and size of the surface may change as the plastic deformation evolves. The constitutive law can combine two yield functions in order to simulate separately the shear failure line and end cap in $\mathrm{p}_{\mathrm{m}}^{\prime}$-q plots (Angus et al., 2015; Homand \& Shao, 2006; Lade, 1977). Many shear failure criteria have been proposed in the literature and will not be listed here (e.g. Jaeger et al., 2007). Nevertheless, two assumptions based on experimental studies can be identified when formulating the constitutive equations. The shear failure line can be assumed as a straight line based on the classical Mohr-Coulomb criteria or as a curved line following the theory of elasto-plasticity taking into account the sensitivity of chalk deformation to the confining stress (Havmøller \& Foged, 1996; Homand \& Shao, 2000; Teufel et al., 1991; Vejbæk et al., 2014; Xie \& Shao, 2006). The second yield function is commonly derived from the modified Cam-Clay model developed for soils (Roscoe \& Burland, 1968). The material parameters controlling the locus and shape of the elliptical end cap in $\mathrm{p}_{\mathrm{m}}^{\prime}-\mathrm{q}$ plots are based on empirical data and account for lithology, type of saturating fluid, stress conditions and time (Angus et al., 2015; Cassiani et al., 2017; Hickman \& Gutierrez, 2007; Vejbæk et al., 2014). Almost all constitutive models use these two kind of yield surfaces independently for shear and pore collapse deformation (Hajiabadi \& Nick, 2020). Computing the stress-strain state of a rock near the intersection between the two yield functions can cause problems for numerical simulations. Alternatively, a few models have used a single enclosed yield function for the whole mechanism (Ehlers, 1995; Lade \& Kim, 1995; Papamichos et al., 1997). A continuous function approximates simultaneously the shear failure line and elliptical end cap. On the other hand, this method does not provide an optimal match with the experimental data. The slope of the shear failure line at low stresses progressively decreases towards stress conditions close to the intersection point in order to connect with the elliptical end cap. Thus, shear stresses tend to be underestimated towards high $\mathrm{p}_{\mathrm{m}}^{\prime}$.

\section{Dataset and methodology}

\subsection{Experiments}

The yield surface is studied for six porosity classes spanning from $30 \%$ to $45 \%$ porosity, with each class including a $2.5 \%$ porosity range. 36 laboratory tests performed on fully oil-saturated 
chalks, and five and seven tests on $20 \%$ water-saturated and fully water-saturated specimens, respectively, are selected from the JCR database (http://jointchalkresearch.org/) in order to characterise the end cap (Christensen, 2007). 37 additional tests on fully oil-saturated chalks are analysed to describe the shear failure line. In total, 137 stress-strain measurements at shear failure and pore collapse are collected in the present study (Figure 2). The shear failure is identified along the stress-strain curve by an abrupt drop in stress withstood by tested specimens. The elastic to elasto-plastic transition is characterised by calculated values $\sigma_{\mathrm{y}, \text { in. }}$ and $\sigma_{\mathrm{y}, \text { fin. }}$ (Figure $2 \mathrm{~b}$ ). The representative yield stress $\sigma_{\mathrm{y}, \text { rep. }}$ is defined which corresponds to the orthogonal projection of the intersection point between the linear elastic and plastic trends to the tangent of stress-strain curve. Under hydrostatic loading, $\sigma_{\mathrm{y}, \text { in. }}, \sigma_{\mathrm{y}, \text { rep. }}$ and $\sigma_{\mathrm{y} \text {,fin. }}$ are referred to as $\sigma_{\text {hy,in., }} \sigma_{\text {hy,rep. }}$ and $\sigma_{\text {hy, fin. }}$ (Figure $\left.2 a\right)$. Each type of yield stress $\left(\sigma_{y, \text { in. }}, \sigma_{y, \text { rep. }}, \sigma_{y, \text { fin }}\right)$ is then plotted into $p_{m}^{\prime}-q$ plot to visualise the elliptical shape of end caps. A quantitative description of their shape is carried out by calculating the aspect ratio b/a of the two half axes of the ellipse. The value of the vertical half axis b equal the maximum deviatoric stress reported at the onset of pore collapse. The average $\sigma_{\text {hy,in. }}$ is used to define the second half axis a.

Oil phase which were used is either the crude oil from the actual hydrocarbon chalk fields or a light laboratory oil, such as isopar-L, soltrol, Exxol-D60 and white oil. Formation water solution is either artificial brine or seawater in equilibrium with chalk. Formation water contains $\mathrm{Na}^{+}, \mathrm{Mg}^{2+}, \mathrm{K}^{+}, \mathrm{Ca}^{2+}, \mathrm{Sr}^{2+}, \mathrm{Cl}^{-}$, and for few tests also $\mathrm{SO}_{4}{ }^{2-}$ and $\mathrm{Ba}^{2+}$. The selected laboratory tests are short-term (few hours-long experiments) classified into three categories: shear failure, uniaxial strain compaction and hydrostatic compaction tests (Figure 1). Hydrostatic stress conditions are characterised by an isotropic load applied to the specimen along the three major directions: the axial and the two orthogonal radial axes. During the uniaxial strain compaction test, the axial stress is increased while no displacement (strain) is allowed in the horizontal plane. Zero radial strain is maintained by adjusting the load applied to the sides of the specimen. The triaxial failure tests are characterised by an early phase of hydrostatic loading until a given stress followed by the stage during which the radial stress is maintained constant and load is applied along the vertical axis. During the tests, linear variable displacement transducers (LVDT) were used to measure the axial strain. The radial strain was also monitored by: 1) strain gauges for most tests; 2) LVDT (samples 16 to 19 and 26); 3) a radial strain belt (samples 12, 21, 29 and 30). The test procedure applied to the oil-saturated specimens are summarised in Table 1.

This article is protected by copyright. All rights reserved. 
The mechanical tests previously performed between 1989 and 2007 and compiled in the JCR database were carried out at the room temperature with a $1.7 \times 10^{-5}$ to $10^{-4} \% / \mathrm{sec}$ strain rate $(0.06$ to $0.36 \% / \mathrm{hr}$ ). The majority of oil-saturated specimens was not cleaned except seven specimens that were flushed with methanol and toluene or oven dried at $110^{\circ} \mathrm{C}$ prior to oil injection (Table 1). The 12 tested specimens containing water in their pore space, were cleaned using the cold flush miscible liquids cleaning technique and oven dried at $110^{\circ} \mathrm{C}$. Whereas seven core plugs were then fully saturated with water, the remaining specimens were saturated with oil and a pre-defined flooding sequence was applied to obtain $20 \% \mathrm{~S}_{\mathrm{w}}$. After the mechanical tests, nuclear magnetic resonance and/or the Dean-Stark measurements were carried out to verify $S_{\mathrm{w}}$. The mechanical tests are carried out on homogeneous, pelagic, mudstone-wackestone specimens of Maastrichtian age. X-ray diffraction analysis indicates that the mineralogical composition predominantly consists of calcite with less than $3 \%$ clay. The average amount of quartz does not exceed $2 \%$ for samples with porosity $>38 \%$. Quartz content progressively increases up to $12.6 \%$ with decreasing porosity for specimens below $35 \%$ porosity (Figure 3 ). The dataset contains samples from Tyra, Eldfisk, Ekofisk, Valhall, Hod, Dan, South Arne, Gorm, Halfdan and Kraka fields in the North Sea.

\subsection{Simulations}

A unique yield function, which captures both the shear failure line and elliptical end cap is chosen in the present study. The function extrapolates trends between experimental data points on the shear failure and pore collapse of chalk for each porosity class. The yield function (F) of Kristiansen \& Plischke (2010) combining the Mohr-Coulomb criterion for shear failure and end cap for pore collapse is selected:

$$
\mathrm{F}\left(\mathrm{p}_{\mathrm{m}}^{\prime}, \mathrm{J}_{2}\right)=\sqrt{\mathrm{J}_{2}}\left(\cos \theta+\frac{\sin \varphi \sin \theta}{\sqrt{3}}\right)-\left(\mathrm{p}_{\mathrm{m}}^{\prime}+T_{0}\right)\left(\frac{\sigma_{\mathrm{hy}}-\mathrm{p}_{\mathrm{m}}^{\prime}}{\sigma_{\mathrm{hy}}+T_{0}}\right)^{\mathrm{m}} \sin \varphi=0
$$

where,

- $\sigma_{\text {hy }}$ is the hydrostatic yield stress.

- $T_{0}$ is the tensile strength which depends on porosity $(\Phi): T_{0}=4.8-6.4 \Phi[\mathrm{MPa}]$.

- $\mathrm{p}_{\mathrm{m}}^{\prime}$ is the mean effective stress.

- $\varphi$ is the angle of internal friction.

- $m$ is a material parameter determining the shape of the end cap.

- $\theta$ is the Lode's angle.

- $\mathrm{J}_{2}$ is the $2^{\text {nd }}$ invariant of the deviatoric stress $\mathrm{q}$ with $\mathrm{J}_{2}=\frac{q}{\sqrt{3}}$ for isotropic radial stresses. 
Eq. 1 is the modified Mohr-Coulomb yield function to include the end cap proposed by Drescher et al. (1995) on sand and first adapted to chalk geomechanics by Papamichos et al. (1997). Four parameters control the shape of yield surface in $p_{m}^{\prime}-q$ plot. The tensile strength $T_{0}$ and $\sigma_{\text {hy }}$ are the intercepts of the yield surface with the negative and positive part of the $\mathrm{x}$-axis, respectively. Lode angle $\theta$ is equal to $-30^{\circ}$, as in standard triaxial tests or during uniaxial compaction tests. The tangent of the friction angle $\varphi$ defines the slope of the shear failure line. The parameter $\mathrm{m}$ approximates the intersecting point between the shear failure line and end cap. A low $\mathrm{m}$ value shifts the transition point along the shear failure line towards high $\mathrm{p}_{\mathrm{m}}^{\prime}$ and deviatoric stress. Thus, the elliptical end cap tends to display a major axis parallel to the y-axis in order to close the yield surface at high confining stresses. Contrary, the transition point is shifted towards lower stress conditions as the parameter $m$ increases, thereby forming an elliptical end cap that becomes progressively elongated along the $\mathrm{x}$-axis. Isotropic linear elastic deformation is assumed to occur when $\mathrm{F}<0$. Shear failure and pore collapse behaviour takes place if the applied stress regime ( $p_{m}^{\prime}$ and $q$ ) is located on the yield surface and thus satisfies the condition $\mathrm{F}=0$. Following the classical soil mechanics procedure, an exponential growth in $\sigma_{\text {hy }}$ values is considered in the plastic regime to account for the hardening effect. The hardening coefficient that controls the slope of stress-strain curves is a function of volumetric plastic strain.

Two types of yield surfaces are studied. The first one is reconstructed based on $\sigma_{y, \text { in. }}$ values collected from the triaxial tests, whereas the second yield surface is based on the $\sigma_{\mathrm{y}, \text { fin. }}$. The yield function reconstructs the yield surface of chalk in four steps:

For the shear failure line, a linear fitting curve is applied to the dataset per porosity class and the porosity-dependent function of $\varphi$ is defined and integrated into Eq. 1.

- The parameter $к$ defined as the ratio between fully water- and oil-saturated $\sigma_{\text {hy }}$ is calculated in order to quantify the sensitivity of $\sigma_{\text {hy }}$ to $S_{w}$. The values of $\sigma_{\text {hy }}$ from triaxial tests carried out at $S_{\mathrm{w}}$ equal to $20 \%$ are assumed to match the $\sigma_{\text {hy }}$ of the same sample as if it would be fully water-saturated.

- For each porosity class, the yield surface is extrapolated between the shear failure line and end cap by incorporating the porosity- and water-dependent functions of $\sigma_{\text {hy }}, \varphi$ and $T_{0}$ into the yield function (Eq. 1). The reconstruction of the yield surface is carried out by adjusting the parameter $\mathrm{m}$ in Eq. 1 during data fitting. The $\mathrm{L} 2$ norm, which adds the square of the distance between experimental and predicted data is used for the error calculation.

This article is protected by copyright. All rights reserved. 
- The resulting porosity-dependent function of parameter $m$ is then incorporated into the yield function (Eq. 1) to build the yield surface of $30 \%$ to $45 \%$ porosity chalk at $0 \%$ and $100 \%$ water saturation in a p's-q-porosity plot.

\section{Results}

\subsection{Yield surface}

For each porosity class, the experimental data derived from individual laboratory studies of the stresses at shear failure and pore collapse show a clear trend (Figure 4; Table S1). The characteristic shape of yield surface composed of the shear failure line and elliptical end cap can be differentiated despite the lack of data for $32.5 \%$ to $37.5 \%$ porosity chalk. In Figure 5, the Mohr-Coulomb criteria are plotted against porosity. A clear inverse trend can be observed between porosity and $\varphi$. It means when porosity increases from 30 to $45 \%$, the friction angle decreases from $c a$. $0.66 \mathrm{rad}$ to $0.5 \mathrm{rad}\left(37.8\right.$ and $\left.28.6^{\circ}\right)$. A high $\varphi$ value of $0.696\left(39.9^{\circ}\right)$ is observed in the 35-37.5 porosity class. Laboratory data also indicate that $S_{0}$ varies from 1 to 3 $\mathrm{MPa}$ as porosity decreases from $45 \%$ to $30 \%$. The inverse trend between $S_{0}$ and porosity (especially for the $32.5 \%$ to $37.5 \%$ porosity classes) is less certain compared to the observed

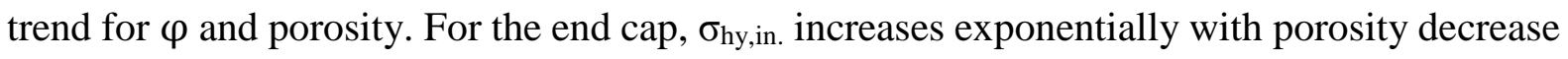
(Figure 5a). The less porous specimens have the mean $\sigma_{\text {hy,in. }}$ of $46.5 \mathrm{MPa}$ while the mean $\sigma_{\text {hy,in. }}$ for high porosity chalk is around $13 \mathrm{MPa}$. Similarly, the maximum deviatoric stress along the end cap varies from $35 \mathrm{MPa}$ to $10 \mathrm{MPa}$ as the porosity increases from $30 \%$ to $45 \%$ (Figure 4). The observed trends between porosity and $\sigma_{\text {hy }}$ and deviatoric stress appear continuous throughout the porosity classes. Besides, these trends are observed for the tree types of end caps that correspond to $\sigma_{y, \text { in., }} \sigma_{y, \text { rep. }}$ and $\sigma_{y}$,in. Thus, the laboratory data indicate the progressive enlargement of yield surface and associated strengthening of chalks towards low porosity values.

\subsection{Locus and shape of end caps}

For each porosity class, the initial and final end caps form parallel curves in the p plots and thus, no significant change in the shape of elliptical end caps is observed across the elastic to elasto-plastic transition zone (Figure 4). However, the width of the transition zone seems to vary with porosity. Considering the eight hydrostatic compaction tests reported in Table 2, the $\sigma_{\text {hy,fin. }} / \sigma_{\text {hy,in. }}$ ratio is between 1.14 and 1.17 for the most porous chalk and increases linearly to 1.29 for the specimens of the lowest porosity class. Note that one test result from sample S9 (porosity $=41.8 \%$ ) does not follow the linear trend even though the $\sigma_{\text {hy,fin }} / \sigma_{\text {hy,in. }}$ ratio of 1.3 is

This article is protected by copyright. All rights reserved. 
within the range of observed values. The progressive widening of elastic to elasto-plastic transition zone by decreasing porosity can also be observed in Figure 5a. The results suggest that $\sigma_{\mathrm{y}, \text { in. }}$ raises by $15 \%$ to $30 \%$ to reach $\sigma_{\mathrm{y} \text {,fin. }}$. The $\sigma_{\mathrm{y} \text {,rep. }}$ is located roughly within the transition zone. The locus variability of $\sigma_{\mathrm{y}, \text { rep. }}$ can be explained by the nature of its estimation (Figure 2 ).

While the shapes of the initial and final end caps do not vary for each porosity class, they alter across the studied porosity range. The shape of end caps changes from an elongated ellipse along the vertical axis to a circle shape as porosity decreases. Considering the $42.5-45 \%$ porosity class, the deviatoric stress at pore collapse equals 6-7 MPa and 8-10 $\mathrm{MPa}$ at the onset and end of transition zone, respectively (Figure 4). These deviatoric stress values remain relatively stable for the wide range of p' values varying between $5 \mathrm{MPa}$ and $11 \mathrm{MPa}$. When $\mathrm{p}_{\mathrm{m}}^{\prime}$ exceeds $12 \mathrm{MPa}$, the deviatoric stress at the onset of pore collapse drops abruptly to zero. Thus, the onset of compaction of $42.5-45 \%$ porosity chalk corresponding to the high $p_{\mathrm{m}}^{\prime}(>11$ $\mathrm{MPa}$ ) appears independent of the amount of applied deviatoric stress. In other words, under high confining pressure, $\mathrm{p}_{\mathrm{m}}^{\prime}$ at pore collapse remains relatively constant (equal to $\sigma_{\text {hy), }}$ even though the applied load deviates from hydrostatic conditions. When $\mathrm{p}_{\mathrm{m}}^{\prime}$ is below the threshold value (11 MPa) for the most porous specimens, pore collapse is initiated at a given deviatoric stress, independently of the applied p p $p_{\mathrm{m}}^{\prime}$. A similar behaviour is also observed for the $40-42.5 \%$ porosity class with fewer data points. On contrary, for the chalk with porosity $<40 \%$, the minimum deviatoric stress required for pore collapse decreases gradually as the amount of $p_{m}^{\prime}$ applied to the specimens increases. Considering the lowest porosity class, the deviatoric stress reduces from $30 \mathrm{MPa}$ to $10 \mathrm{MPa}$ as the applied $\mathrm{p}_{\mathrm{m}}^{\prime}$ raises from $20 \mathrm{MPa}$ to $42 \mathrm{MPa}$. Thereby, under high confining pressure, the difference between the maximum and minimum principal stresses plays a more important role in controlling the onset of compaction of low porosity chalks than for the highly porous counterparts. In order to quantify the change in the elliptical shape of the end caps between porosity classes, the aspect ratio b/a of the two half axes of the ellipse in $p_{m}^{\prime}-\mathrm{q}$ plot is calculated (Figure 4). The aspect ratio exceeds 1.24 for chalks with a porosity above $37.5 \%$, whereas it remains relatively stable and equal $c a .1$ (0.98 to 1.07) for less porous chalks. Thus, the elliptical end cap becomes elongated along the vertical axis of $\mathrm{p}_{\mathrm{m}}^{\prime}$-q plot when chalk porosity exceeds $37.5 \%$.

\subsection{Water weakening effect}

The water weakening effect on rock strength in an oil-water saturated chalk is estimated by the parameter к as:

This article is protected by copyright. All rights reserved. 


$$
\sigma_{\mathrm{hy}}\left(\mathrm{S}_{\mathrm{w}}=1\right)=\kappa * \sigma_{\mathrm{hy}}\left(\mathrm{S}_{\mathrm{w}}=0\right)
$$

A total of 12 triaxial tests carried out on $20 \%$ and $100 \%$ water-saturated specimens is used to calibrate the ratio of $к$ (Table 3). In order to calculate $\kappa$ for chalks at a given $S_{\mathrm{w}}$, an estimation of $\sigma_{\text {hy }}$ for the same sample that is fully saturated by oil is required. Predicting $\sigma_{\text {hy }}$ of chalks are based on porosity-dependent functions, which are associated with a non-negligible uncertainty due to data scattering as shown in Figure 5a and in other studies (Havmøller \& Foged, 1996; Hickman, 2004). The results of hydrostatic compaction tests on fully oil-saturated specimens provides key information to constrain such uncertainty and ultimately, to allow for a better assessment of the water weakening effect (Table 2). As mentioned earlier, the elastic to elasto-

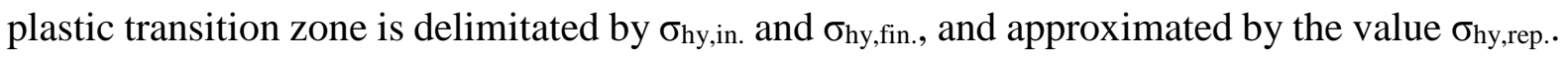
Thus, three values of parameter $\kappa$ are estimated for each hydrostatic compaction test carried out on $20 \%$ and $100 \% S_{\mathrm{w}}$ specimens. While the mean $\sigma_{\text {hy,rep. }}\left(S_{\mathrm{w}}=0\right)$ value per porosity class is used to approximate the к value, the mean $\sigma_{\text {hy,in. }}\left(S_{\mathrm{w}}=0\right)$ and $\sigma_{\text {hy,fin. }}\left(S_{\mathrm{w}}=0\right)$ are used to calculate the maximum and minimum values of $\kappa$. Due to lack of experimental data for the $35-37.5 \%$

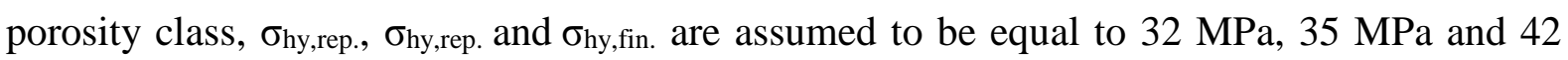
$\mathrm{MPa}$, respectively (Figure 4). The $к$ values illustrated in Figure 6 suggest that the water weakening effect varies as a function of porosity (Figure 6). While a 35\% reduction in rock strength due to the water weakening is estimated for the most porous specimens, the mechanical weakening becomes insignificant for the low porosity chalks. A linear relationship quantifying the maximum impact of water weakening effect on $\sigma_{\text {hy }}$ of oil-saturated chalk is identified and expressed as:

$$
\kappa=-2.06 \Phi+1.5
$$

where $\Phi$ is in fraction.

\section{Discussion}

\subsection{Yield surface}

\subsubsection{Yield function}

According to Eq. (1), the reconstruction of yield surface requires the estimation of $\varphi$ and $\sigma_{\text {hy }}$ of chalk for a given porosity and $S_{\mathrm{w}}$, and the $\mathrm{m}$ parameter across the studied porosity range. These are estimated through the following steps: 1) The experimental results from shear failure tests are used to estimate the porosity-dependency of $\varphi$ (shown in Figure 5b). 2) $\sigma_{\text {hy }}$ of chalk in MPa depends on porosity and $\mathrm{S}_{\mathrm{w}}$ and it is estimated by:

This article is protected by copyright. All rights reserved. 


$$
\begin{aligned}
& \text { for } S_{\mathrm{w}}=0 \text { and } 0.30<\Phi<0.45: \sigma_{\mathrm{hy}}(\Phi)=1180 e^{(-10.3 \Phi)} \\
& \text { for } S_{\mathrm{w}}=1 \text { and } 0.30<\Phi<0.45: \sigma_{\mathrm{hy}}(\Phi)=\left[1180 e^{(-10.3 \Phi)}\right](-2.06 \Phi+1.5)
\end{aligned}
$$

The $\sigma_{\text {hy,in. }}$ is considered in Eqs 4 and 5 to build the yield surface as the $\sigma_{\text {hy,rep. }}$ values are less accurate and $\sigma_{\text {hy, fin. }}$ does not cover the full range of stresses at which plastic deformation occurs

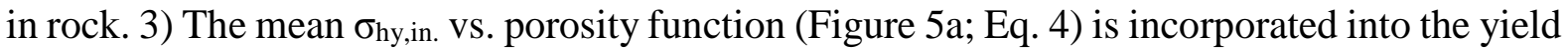
function (Eq. 1). For each porosity class, the calibration of the parameter $\mathrm{m}$ is carried out by adjusting its value using the L2 norm for error minimisation between the experimental and simulation data (Figure 7). A smooth stepwise function (Figure 8) is then selected to estimate the parameter $\mathrm{m}$ as a function of porosity:

$$
\mathrm{m}=\frac{0.64 \mathrm{e}^{\left(106 \Phi_{\mathrm{c}}\right)}+0.33 \mathrm{e}^{(106 \Phi)}}{\mathrm{e}^{\left(106 \Phi_{\mathrm{c}}\right)}+\mathrm{e}^{(106 \Phi)}}
$$

where 0.64 and 0.33 are the maximum and minimum values of $\mathrm{m}$ and the inflection point of the function is a critical porosity $\left(\Phi_{c}\right)$ equal to 0.4 .

The results indicate that the $\mathrm{m}$ parameter increases from 0.35 to 0.65 when chalk porosity is below $40 \%$. The change of values of $m$ indicates that the elliptical shape of end caps becomes elongated along the $\mathrm{x}$-axis of $\mathrm{p}_{\mathrm{m}}^{\prime} \mathrm{q}$ plot as porosity decreases. This is in agreement with experimental observations on the aspect ratio b/a of the end caps (shown in Figure 4). The aspect ratio describes an elongated ellipse along the vertical axis for chalk with porosity $>37.5 \%$ while a circle shape is observed for less porous chalk.

4) The empirical functions (Eqs 3 to 6) are substituted into the yield function (Eq. 1) to reconstruct the initial yield surface of chalk with porosity between $30 \%$ to $45 \%$ :

for $S_{\mathrm{w}}=0$ :

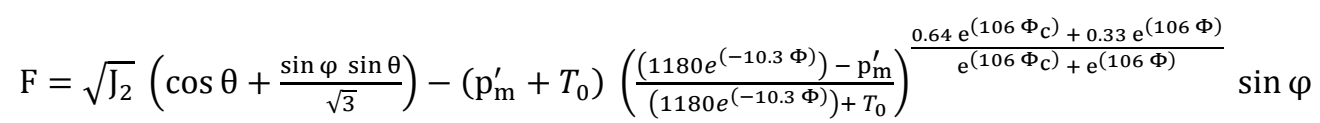

for $S_{\mathrm{w}}=1$ :

$\mathrm{F}=\sqrt{\mathrm{J}_{2}}\left(\cos \theta+\frac{\sin \varphi \sin \theta}{\sqrt{3}}\right)-\left(\mathrm{p}_{\mathrm{m}}^{\prime}+T_{0}\right)\left(\frac{\left(1180 e^{(-10.3 \Phi)}\right)(-2.06 \Phi+1.5)-\mathrm{p}_{\mathrm{m}}^{\prime}}{\left(1180 e^{(-10.3 \Phi)}\right)(-2.06 \Phi+1.5)+T_{0}}\right)^{\frac{0.64 \mathrm{e}^{\left(106 \Phi_{\mathrm{c}}\right)}+0.33 \mathrm{e}^{(106 \Phi)}}{\mathrm{e}^{\left(106 \Phi_{\mathrm{c}}\right)}+\mathrm{e}^{(106 \Phi)}}} \sin \varphi$

Note that $T_{0}(\Phi)$ and $\varphi(\Phi)$ relationships are defined in Eq. (1) and Figure 5b, respectively.

This article is protected by copyright. All rights reserved. 
These proposed relations capture both the strengthening and softening behaviour of chalk depending on porosity and $S_{\mathrm{w}}$ (Figures 9,10 ). Along the yield surface when changing porosity from $32.5 \%$ to $45 \%$, the $\sigma_{\text {hy }}$ and maximum deviatoric stresses of oil-saturated chalk increase from $12 \mathrm{MPa}$ and $8 \mathrm{MPa}$ to $42 \mathrm{MPa}$ and $25 \mathrm{MPa}$, respectively. When water is present in the pore space, the $\sigma_{\text {hy }}$ and maximum deviatoric stresses are reduced to $7 \mathrm{MPa}$ and $5 \mathrm{MPa}$ and to $36 \mathrm{MPa}$ and $21 \mathrm{MPa}$, respectively, as porosity increases. Change in the shape of end caps between low and high porosity chalks observed in the experimental data and during statistical analysis (Figures 4, 7), is also captured by the model (Figure 9). Furthermore, the constitutive model (Eq. 1) is incorporated into Comsol Multiphysics software and tested against results of a number of hydrostatic (Figure S1) and uniaxial strain compaction tests (Figures S2, S3). After calibrating the elastic moduli, poisson's ratio and hardening coefficient, the yield function reproduces well the stress-strain and radial-axial stress curves measured during the experiments.

\subsubsection{Data representativeness}

Comprehensive studies on the petrophysical and geomechanical properties of Upper Cretaceous chalks have pointed out general trends between porosity and permeability, Young's modulus, $T_{0}, \varphi$ and $\sigma_{\mathrm{y}}$ common to different hydrocarbon fields (Fabricius et al., 2007; Havmøller \& Foged, 1996; Hickman, 2004; Jakobsen et al., 2004; Røgen \& Fabricius, 2002). Similarly, in the present study, the plotting of over 130 stress-strain measurements at the shear failure and pore collapse in $\mathrm{p}_{\mathrm{m}}^{\prime} \mathrm{q}$ p plot forms coherent yield surfaces indicating consistency in the mechanical behaviour of specimens collected in different North Sea chalk reservoirs. However, these comprehensive studies also show a non-negligible scattering of data at a given porosity along trends that can raise questions about the representativeness of reported correlations. Such uncertainty is caused by the depositional and diagenetic history of each reservoir that governs the specific texture, mineralogy and degree of calcite recrystallisation and cementation of chalks with a similar porosity (Descamps et al., 2017; Fabricius, 2003; Fabricius et al., 2008; Lindgreen et al., 2012). In the present study, the selected tests are carried out on clean pelagic mudstones and wackestones of Upper Cretaceous age compiled into six porosity groups (Figure 3; Table 1). Thus, variations in the degree of recrystallisation and cementation of rock fabrics among the studied hydrocarbon fields and over a $2.5 \%$ porosity range are the two main factors that can explain the data scattering associated with the reported trends (Figures 5, 7, 8). The present study aims to provide a general framework for the mechanical behaviour of the main reservoir rock type in the Danish North Sea over a 30-45\%

This article is protected by copyright. All rights reserved. 
porosity range. The correlation functions, which are presented in a concise way can then be adjusted to accurately fit the specific characteristics of a given reservoir.

\subsection{Water weakening effect: role of quartz}

The water weakening effect results from several physico-chemical processes acting over a short- and long-term period, from few minutes to months (P. Ø. Andersen et al., 2018; Heggheim et al., 2005; Korsnes et al., 2008; Loe et al., 1992; Megawati et al., 2013; Minde et al., 2018; Risnes et al., 2005; Røyne et al., 2015). The triaxial tests reported in the present study are typically short-term (few hours-long) experiments carried out at room temperature. Adsorption of ions from the water phase on the calcite surface is thought to control the observed water weakening effect (Risnes et al., 2005). Interestingly, laboratory studies suggest that the impact of $S_{\mathrm{w}}$ on the rock strength varies between outcrop and subsurface chalks (Tables 3, 4). While the $\sigma_{\text {hy }}$ of oil-saturated outcrop samples with a porosity between 34 and $44 \%$ is systematically reduced by $c a$. $50 \%$ when saturated with water, the water weakening effect appears to be porosity dependent for reservoir chalk as shown in Figure 6. The observed trend for reservoir chalk is in agreement with previous geomechanical modelling studies, which considered that the water weakening effect becomes less significant as porosity decreases (Hickman, 2004; Kristiansen \& Plischke, 2010; Vejbæk et al., 2014). Consequently, in addition to adsorption, other parameters, such as wettability and mineralogy, need to be investigated to explain the differences observed between outcrop and reservoir chalk with a similar porosity. Outcrop specimens tend to be strongly water-wet, whereas the wettability of subsurface chalk varies between slightly water-wet to slightly oil-wet (Andersen, 1995). Such difference in wettability that may be, in theory, limited by the rock cleaning procedure, can influence the water weakening effect through controlling the available total surface area of grains, on which ions from the water phase can adhere. Oil-wet chalk displays a lower calcite-water surface area compared to their water-wet counterparts. During burial, porosity preservation of chalk is, amongst others, enhanced by the presence of oil in pore space (Hardman, 1982). Thus, the most porous reservoir specimens tested are the ones that display slightly oil-wet conditions and thereby, a reduced water weakening effect. However, an opposite trend is observed in the dataset shown in Figure 6 . The decrease of the $\sigma_{\text {hy }}$ when replacing oil by water in pore space becomes less significant as porosity declines. Thus, there is no direct correlation between the assumed rock wettability and the water weakening effect observed in the tests. Another variable is the silica content in chalk. The silica content that does not exceed 5\% in the outcrop specimens (Table 4), reaches up to $12.6 \%$ in the less porous reservoir specimens as shown in 
Figure 3. Silica is present in the form of micro-quartz that consists of nano-spheres $(\approx 500 \AA$ in diameter) connected to each other to form micro-scale aggregates with a granular structure (Lindgreen et al., 2012; Maliva \& Dickson, 1992). Such a quartz cement surrounding calcite grains strengthens grain contacts, similar to calcite recrystallisation and cementation processes (Fabricius, 2003; da Silva et al., 1985). The development of disjoining pressure or repulsive hydration force between grains with the presence of water in the pore space may be hindered by the presence of micro-quartz bridging calcite grains. The short-term water weakening effect caused by the adsorption of ions from the water phase on the calcite grains can thus be reduced for the studied low porosity reservoir chalk compared to that of the outcrop chalk.

\subsection{Yield surface of reservoir chalk}

The reported experimental data show the expansion and shrinkage of the yield surfaces depending on porosity and $S_{\mathrm{w}}$ (Figures 9,10 ). These observations on the locus of the yield surfaces and the reported values of $\sigma_{\mathrm{y}}$ are in agreement with previous experimental and simulation studies on pelagic Maastrichtian chalk (e.g. Havmøller \& Foged, 1996; Kristiansen $\&$ Plischke, 2010; Vejbæk et al., 2014). The results also indicate that the width of the elastic to elasto-plastic transition zone and the curvature of end cap vary with porosity. First, the stress

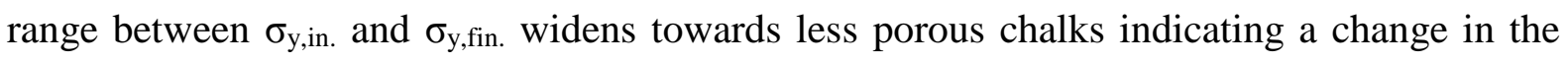
cascade of failure-stress redistribution that occurs at pore collapse. For clean pelagic chalk from the North Sea reservoirs, calcite cementation is a major porosity-destructive process, which can explain the observed variation in the width of the elastic to elasto-plastic transition zone (Fabricius, 2003). The rock fabric of a highly porous chalk displays a poorly-cemented solid skeleton. When the applied stress reaches $\sigma_{y}$,in. and pore collapse is initiated, the cascade of failure-stress redistribution spreads rapidly throughout the weak rock matrix and prevents permeability enhancement (Leddra, 1989; Andersen, 1995). On contrary, less porous rock displays both well-cemented and poorly-cemented areas caused by calcite overgrowth and precipitation in intraparticle pores (Hjuler \& Fabricius, 2009). Local pore-filling cementation can cause contrasts in the strength of pore walls and contact cements throughout the rock fabric. At pore collapse, the weakest areas fail first and form micro-cracks, which temporary enhance permeability (Leddra, 1989). A deviation of the stress-strain curve from an assumed linear elastic behaviour can then be observed (identified as $\sigma_{y}$,in.). However, the local failure of cemented and stronger areas of the rock requires a higher stress level. Therefore, the stress range between the elastic to elasto-plastic regime is widened.

This article is protected by copyright. All rights reserved. 
Second, the shape of elliptical end caps in $\mathrm{p}_{\mathrm{m}}^{\prime}-\mathrm{q}$ plots varies from elongated along the vertical axis to a rounded shape as porosity decreases (Figures 4,7,8). This change in the curvature of end caps can reflect either the influence of boundary conditions of the test procedure or the actual mechanical behaviour of chalk. On one hand, the studied tests are deformationcontrolled experiments during which strain rate is maintained constant. For highly porous chalk, the measured total strain per unit of time rises abruptly due to the onset of plastic deformation at pore collapse. In this case, the fixed strain rate becomes temporary too low compared to the inherent rate of deformation of the collapsing specimen, thereby causing a softening effect (Omdal et al., 2010). For chalk with a porosity $>37.5 \%$, the elongated shape of the elliptical end cap along the vertical axis of $p_{m}^{\prime}-q$ plot can result from the latter softening effect that reduces $\sigma_{\mathrm{y}}$ for different stress paths and, ultimately, shifts the end cap towards lower $p_{m}^{\prime}$ values. On the other hand, the change in the curvature of end caps can suggest that the impact of stress anisotropy on the onset of plastic deformation varies with porosity. For $<37.5 \%$ porosity chalk, $\mathrm{p}_{\mathrm{m}}^{\prime}$ at pore collapse is systematically reduced when a shear component is present in the applied load. This mechanical behaviour has been observed in chalk and porous limestones (Curran \& Carroll, 1979; Kågeson-Loe et al., 1993; Vajdova et al., 2012). The rigid skeleton of rocks withstand pressure while shear stress concentrates in the mechanically weakest features of the rock matrix (e.g. large pores and poorly-cemented areas), thereby promoting their mechanical instability and subsequent collapse. For specimens with a porosity $>37.5 \%$, the elongated shape of end caps along the vertical axis of $p_{m}^{\prime}-q$ plot indicates that $\sigma_{\mathrm{y}}$ is less sensitive to the stress anisotropy, thereby indicating a variation in the compaction mechanisms compared with that of less porous chalk. Pore collapse tends to occur at a critical

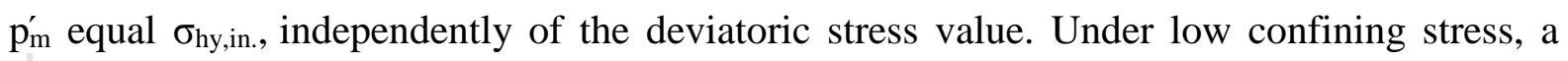
critical deviatoric stress, for instance equal 7-8 MPa for the $42.5-45 \%$ porosity class, is observed. Above this deviatoric stress value, pore collapse is initiated independently of $\mathrm{p}_{\mathrm{m}}^{\prime}$. Contrary to the low porosity specimens in which local stress concentration controls the onset of compaction, the rock fabric of highly porous chalk appears to behave homogeneously failing at given mean and deviatoric stress thresholds. The rock fabric of high porosity chalk mainly consists of individual calcite grains connected by contact cements and well-cemented areas are scarce (Fabricius et al., 2008). A significant fraction of contact cements likely fails at the same mean and deviatoric stress conditions. The slightly stronger contact cements may also rapidly fail by propagation of the cascade of failure-stress redistribution. To conclude, the porositydependence of the width of elastic to elasto-plastic transition zone and curvature of end caps

This article is protected by copyright. All rights reserved. 
may be dictated by the type and distribution of calcite cement that strengthens the solid skeleton of clean pelagic reservoir chalks from the North Sea.

\section{Conclusion}

The present study aims at reconstructing, for the first time in p p-q-porosity plot, the end cap and shear failure line of intact Upper Cretaceous pelagic chalk based on experimental data carried out on reservoir samples. Specimens with $S_{\mathrm{w}}$ equal to $0 \%, 20 \%$ and $100 \%$ and porosity values ranging from $30 \%$ to $45 \%$ are investigated in order to cover a wide spectrum of reservoir rock types that are likely to deform plastically in a producing field. Specific attention is brought to the evolution of the $\sigma_{\mathrm{y}}$ and the shape of end cap with porosity and $S_{\mathrm{w}}$. The experimental data capture the hardening and softening of rock strength with decreasing initial porosity and increasing initial $S_{\mathrm{w}}$, respectively. Further characteristics of the mechanical behaviour of chalk are also reported. Within $p_{m}^{\prime}-q$ plots, the width of the elastic to elasto-plastic transition zone narrows towards highly porous specimens, while the elliptical shape of the end cap becomes elongated along the vertical axis of the plot. These two trends may suggest changes in the physical pore-scale processes acting in the rock matrix at the onset of compaction. For chalk with a porosity $>37.5 \%$, the collapse of pores rapidly spreads throughout the weak rock matrix once the applied stress reaches a critical mean or deviatoric stress. As porosity declines, the rock fabric displays patches of well-cemented and poorly-cemented areas, which imply contrasts in the local stiffness of pores and contact cements. Thus, the stress range, at which the cascade of failure-stress redistribution occurs becomes wider than for the high porosity counterparts.

Furthermore, the results indicate that the impact of $S_{\mathrm{w}}$ on rock strength differs between the outcrop and reservoir chalk. The water weakening effect is porosity dependent for reservoir chalk and becomes almost insignificant for low porosity specimens ( $<32.5 \%$ porosity). For outcrop specimens, a steady $50 \%$ decrease in the $\sigma_{\text {hy }}$ is reported across a $34-44 \%$ porosity range. Contrarily to outcrop chalk at similar porosity, a non-negligible proportion of quartz is present in the tested reservoir specimens. Quartz that forms a cement surrounding calcite grains and strengthening grain contacts may reduce the impact of $S_{w}$ on the mechanical properties of chalk. Care should therefore be given when selecting outcrop samples as geomechanical analogues to reservoir chalk from the Danish North Sea. Besides, a yield function is proposed to build the yield surface of reservoir chalk together with a method to capture the porositydependent change in the shape of end cap and the water weakening effect. The outcomes of

This article is protected by copyright. All rights reserved. 
this study provide key input data describing and quantifying the mechanical behaviour and properties of chalk under laboratory conditions required for reliable prediction of reservoir compaction.

\section{Acknowledgement}

The research leading to these results has received funding from the Danish Hydrocarbon Research and Technology Centre under the Advanced Water Flooding program. All geomechanics data used in this study are compiled in the JCR database and can be accessible upon registration from http://jointchalkresearch.org/ using the file numbers compiled in Table 1.

\section{References}

Andersen, M. A. (1995). Petroleum research in North Sea chalk. North. Stavanger, Norway: Rogaland Research.

Andersen, M. A., Foged, N., \& Pedersen, H. E. (1992). The rate-type compaction of a weak North Sea chalk. In 4th North Sea Chalk Symposiumm (pp. 253-262). Deauville.

Andersen, P. Ø., Wang, W., Madland, M. V., Zimmermann, U., Korsnes, R. I., Bertolino, S. R. A., et al. (2018). Comparative Study of Five Outcrop Chalks Flooded at Reservoir Conditions: Chemo-mechanical Behaviour and Profiles of Compositional Alteration. Transport in Porous Media, 121(1), 135-181. https://doi.org/10.1007/s11242-017-0953-6

Angus, D. A., Dutko, M., Kristiansen, T. G., Fisher, Q. J., Kendall, J. M., Baird, A. F., et al. (2015). Integrated hydro-mechanical and seismic modelling of the Valhall reservoir: A case study of predicting subsidence, AVOA and microseismicity. Geomechanics for Energy and the Environment, 2, 32-44. https://doi.org/10.1016/j.gete.2015.05.002

Boade, R. R., Chin, L. Y., \& Siemers, W. T. (1989). Forecasting of Ekofisk reservoir compaction and subsidence by numerical simulation. Journal of Petroleum Technology, 41, 723-728. https://doi.org/10.2118/17855-pa

Cassiani, G., Brovelli, A., \& Hueckel, T. (2017). A strain-rate-dependent modified Cam-Clay model for the simulation of soil/rock compaction. Geomechanics for Energy and the Environment, 11, 42-51. https://doi.org/10.1016/j.gete.2017.07.001

Christensen, H. F. (2007). Joint Chalk Research, Phase 6: Database update, standard curves and data input tool. Lyngby. Retrieved from http://jointchalkresearch.org/report/database-update-standard-curves-anddata-input-tool

Collin, F., Cui, Y. J., Schroeder, C., \& Charlier, R. (2002). Mechanical behaviour of Lixhe chalk partly saturated by oil and water: Experiment and modelling. International Journal for Numerical and Analytical

This article is protected by copyright. All rights reserved. 
Methods in Geomechanics, 26(9), 897-924. https://doi.org/10.1002/nag.229

Curran, J. H., \& Carroll, M. M. (1979). Shear stress enhancement of void compaction. Journal of Geophysical Research, 84(B3), 1105-1112. https://doi.org/10.1029/jb084ib03p01105

Delage, P., Schroeder, C., \& Cui, Y. J. (1996). Subsidence and capillary effects in chalks. In Proceedings of the Eurock 96 (pp. 1291-1298). Turin. Retrieved from http://arxiv.org/abs/0803.1308

Descamps, F., Faÿ-Gomord, O., Vandycke, S., Schroeder, C., Swennen, R., \& Tshibangu, J. P. (2017). Relationships between geomechanical properties and lithotypes in NW European chalks. Geological Society Special Publication, 458, 227-244. https://doi.org/10.1144/SP458.9

Drescher, A., Birgisson, B., \& Shah, K. (1995). A model for water-saturated sand. In G. N. Pande \& S. Pietruszczak (Eds.), Proc. NUMOG V, Numerical models in Geomechanics (pp. 209-212). Davos: Balkema.

Ehlers, W. (1995). A single-surface yield function for geomaterials. Applied Mechanics, 65, 246-259. https://doi.org/10.1007/BF00805464

Fabricius, I. L. (2003). How burial diagenesis of chalk sediments controls sonic velocity and porosity. $A A P G$ Bulletin, 87(11), 1755-1778. https://doi.org/10.1306/06230301113

Fabricius, I. L. (2007). Chalk: Composition, diagenesis and physical properties. Bulletin of the Geological Society of Denmark, 55, 97-128.

Fabricius, I. L., \& Borre, M. K. (1998). Chemical and mechanical processes during burial diagenesis of chalk: An interpretation based on specific surface data of deep-sea sediments. Sedimentology, 54, 183-205. https://doi.org/10.1046/j.1365-3091.1998.00178.x

Fabricius, I. L., Rogen, B., \& Gommesen, L. (2007). How depositional texture and diagenesis control petrophysical and elastic properties of samples from five North Sea chalk fields. Petroleum Geoscience, 13(1), 81-95. https://doi.org/10.1144/1354-079306-707

Fabricius, I. L., Gommesen, L., Krogsbøll, A., \& Olsen, D. (2008). Chalk porosity and sonic velocity versus burial depth: Influence of fluid pressure, hydrocarbons, and mineralogy. AAPG Bulletin, 92(2), 201-223. https://doi.org/10.1306/10170707077

De Gennaro, V., \& Pereira, J. M. (2013). A viscoplastic constitutive model for unsaturated geomaterials. Computers and Geotechnics, 54, 143-151. https://doi.org/10.1016/j.compgeo.2013.06.005

De Gennaro, V., Delage, P., Priol, G., Collin, F., \& Cui, Y. . (2004). On the collapse behaviour of oil reservoir chalk. Géotechnique, 54(6), 415-420. https://doi.org/10.1680/geot.2004.54.6.415

Goulty, N. R. (2003). Reservoir stress path during depletion of Norwegian chalk oilfields. Petroleum Geoscience, 9, 233-241. https://doi.org/10.1144/1354-079302-545

Hajiabadi, M., \& Nick, H. M. (2020). A modified strain rate dependent constitutive model for chalk and porous rock. International Journal of Rock Mechanics and Mining Sciences, 134, 1-12.

This article is protected by copyright. All rights reserved. 
Hardman, R. F. P. (1982). Chalk reservoirs of the North Sea. Bulletin of the Geological Society of Denmark, 30 , $119-137$.

Havmøller, O., \& Foged, N. (1996). Review of rock mechanics data for chalk. In V North Sea chalk symposium (pp. 1-26). reims.

Heggheim, T., Madland, M. V., Risnes, R., \& Austad, T. (2005). A chemical induced enhanced weakening of chalk by seawater. Journal of Petroleum Science and Engineering, 46(3), 171-184. https://doi.org/10.1016/j.petrol.2004.12.001

Hickman, R. J. (2004). Formulation and implementation of a constitutive model for soft rock (Doctoral dissertation). Virginia Polytechnic Institute and State University, Blacksburg, VA. Retrieved from http://hdl.handle.net/10919/29000

Hickman, R. J., \& Gutierrez, M. S. (2007). Formulation of a three-dimensional rate-dependent constitutive model for chalk and porous rocks. International Journal for Numerical and Analytical Methods in Geomechanics, 31(4), 583-605. https://doi.org/10.1002/nag.546

Hjuler, M. L., \& Fabricius, I. L. (2009). Engineering properties of chalk related to diagenetic variations of Upper Cretaceous onshore and offshore chalk in the North Sea area. Journal of Petroleum Science and Engineering, 68(3-4), 151-170. https://doi.org/10.1016/j.petrol.2009.06.005

Homand, S., \& Shao, J. F. (2000). Mechanical behaviour of a porous chalk and effect of saturating fluid. Mechanics of Cohesive-Frictional Materials, 5(7), 583-606. https://doi.org/10.1002/10991484(200010)5:7<583::AID-CFM110>3.0.CO;2-J

Homand, S., \& Shao, J. F. (2006). Mechanical Behaviour of a Porous Chalk and Water/Chalk Interaction. Part Ii: Numerical Modelling. Oil \& Gas Science and Technology, 55(6), 599-609. https://doi.org/10.2516/ogst:2000045

Jaeger, J. C., Cook, N. G. W., \& Zimmerman, R. (2007). Fundamentals of rock mechanics (4th ed.). Malden, USA: Blackwell Publishing Ltd.

Jakobsen, F., Ineson, J. R., Kristensen, L., \& Stemmerik, L. (2004). Characterization and zonation of a marly chalk reservoir: the Lower Cretaceous Valdemar Field of the Danish Central Graben. Petroleum Geoscience, 10(1), 21-33. https://doi.org/10.1144/1354-079303-584

Johnsen, Ø., Cuisiat, F., \& Grande, L. (2011). Effects of loading rate and saturating fluid on chalk mechanical behavior. In 9th Euroconference on Rock Physics and Geomechanics (pp. 1-20). Trondheim.

Kågeson-Loe, N. M., Jones, M. E., Petley, D. N., \& Leddra, M. J. (1993). Fabric evolution during the deformation of chalk. International Journal of Rock Mechanics and Mining Sciences and Geomechanics, 30(7), 739-745. https://doi.org/10.1016/0148-9062(93)90016-7

Korsnes, R. I., Madland, M. V., Austad, T., Haver, S., \& Røsland, G. (2008). The effects of temperature on the water weakening of chalk by seawater. Journal of Petroleum Science and Engineering, 60(3-4), 183-193. https://doi.org/10.1016/j.petrol.2007.06.001

This article is protected by copyright. All rights reserved. 
Kristiansen, T., \& Plischke, B. (2010). History Matched Full Field Geomechanics Model of the Valhall Field Including Water Weakening and Re-Pressurisation. SPE, 1-21. https://doi.org/10.2523/131505-ms

Lade, P. V. (1977). Elasto-plastic stress-strain theory for cohesionless soil with curved yield surfaces. International Journal of Solids and Structures, 13(11), 1019-1035. https://doi.org/10.1016/00207683(77)90073-7

Lade, P. V., \& Kim, M. K. (1995). Single hardening constitutive model for soil, rock and concrete. International Journal of Solids and Structures, 32(14), 1963-1978. https://doi.org/10.1016/0020-7683(94)00247-T

Leddra, M. J. (1989). Deformation of chalk through compaction and flow (Doctoral dissertation). University College London, London, UK.

Lindgreen, H., Fallick, A. E., Jakobsen, F., \& Springer, N. (2012). The tight danian ekofisk chalk reservoir formation in the south arne field, north sea: Mineralogy and porosity properties. Journal of Petroleum Geology, 35(3), 291-309. https://doi.org/10.1111/j.1747-5457.2012.00531.x

Loe, N., Mathiesen, E., Jones, M., \& Leddra, M. (1992). The Influence of Changes in the Pore Fluid on the OneDimensional Compaction Behaviour of Chalk. In 4th North Sea Chalk Symposium. Deauville.

Ma, T., Wei, C., Chen, P., \& Li, W. (2019). Chemo-mechanical coupling constitutive model for chalk considering chalk-fluid physicochemical interaction. Géotechnique, 69(4), 308-319. https://doi.org/10.1680/jgeot.17.p.115

Maliva, A. J., \& Dickson, J. A. D. (1992). Microfacies and diagenetic controls of porosity in Cretaceous/Tertiary chalk, Eldfisk field, Norwegian North Sea. AAPG Bulletin, 76(11), 1825-1838.

Medetbekova, M. K., Christensen, H. F., Salimzadeh, S., Bakker, R. R., \& Nick, H. M. (2020). Experimental Investigation of Drilling Lateral Boreholes in Chalk Rocks with High Pressure Jets. International Journal of Geomechanics, 20(6), 1-24.

Megawati, M., Hiorth, A., \& Madland, M. V. (2013). The Impact of Surface Charge on the Mechanical Behavior of High-Porosity Chalk. Rock Mechanics and Rock Engineering, 46(5), 1073-1090. https://doi.org/10.1007/s00603-012-0317-z

Minde, M. W., Wang, W., Madland, M. V., Zimmermann, U., Korsnes, R. I., Bertolino, S. R. A., \& Andersen, P. (2018). Temperature effects on rock engineering properties and rock-fluid chemistry in opal-CTbearing chalk. Journal of Petroleum Science and Engineering, 169, 454-470. https://doi.org/10.1016/j.petrol.2018.05.072

Mohr, O. (1900). Welche Umstände bedingen die Elastizitätsgrenze und den Bruch eines Materials? Zeitschrift Des Vereines Deutscher Ingenieure, 44(45), 1524-1530.

Nermoen, A., Korsnes, R. I., Aursjø, O., Madland, M. V., Kjørslevik, T. A. C., \& Østensen, G. (2016). How Stress and Temperature Conditions Affect Rock-Fluid Chemistry and Mechanical Deformation. Frontiers in Physics, 4(February), 1-19. https://doi.org/10.3389/fphy.2016.00002

This article is protected by copyright. All rights reserved. 
Omdal, E., Madland, M. V., Kristiansen, T. G., Nagel, N. B., Korsnes, R. I., \& Hiorth, A. (2010). Deformation Behavior of Chalk Studied Close to In Situ Reservoir Conditions. Rock Mechanics and Rock Engineering, 43(5), 557-580. https://doi.org/10.1007/s00603-010-0087-4

Papamichos, E., Brignoli, M., \& Santarelli, F. J. (1997). Experimental and theoretical study of a partially saturated collapsible rock. Mechanics of Cohesive-Frictional Materials, 2(3), 251-278. https://doi.org/10.1002/(SICI)1099-1484(199707)2:3<251::AID-CFM33>3.0.CO;2-\#

Risnes, R., \& Flaageng, O. (1999). Mechanical properties of chalk with emphasis on chalk-fluid interactions and micromechanical aspects. Oil and Gas Science and Technology, 54(6), 751-758. https://doi.org/10.2516/ogst:1999063

Risnes, R., Garpestad, O. J., Gilje, M., Oland, L. T., \& Ovesen, M. (1998). Strain hardening and extensional failure in high porosity chalk. In SPE/ISRM Eurock 98 (pp. 475-484). Trondheim.

Risnes, R., Madland, M. V., Hole, M., \& Kwabiah, N. K. (2005). Water weakening of chalk - Mechanical effects of water-glycol mixtures. Journal of Petroleum Science and Engineering, 48(1-2), 21-36. https://doi.org/10.1016/j.petrol.2005.04.004

Røgen, B., \& Fabricius, I. L. (2002). Influence of clay and silica on permeability and capillary entry pressure of chalk reservoirs in the North Sea. Petroleum Geoscience, 8, 287-293.

Roscoe, K. ., \& Burland, J. B. (1968). On the generalized stress-strain behavior of "wet” clay. Engineering Plasticity, 535-609. https://doi.org/10.1016/0022-4898(70)90160-6

Røyne, A., Dalby, K. N., \& Hassenkam, T. (2015). Repulsive hydration forces between calcite surfaces and their effect on the brittle strength of calcite-bearing rocks. Geophysical Research Letters, 42, 4786-4794. https://doi.org/10.1002/2015GL064365

Ruddy, I., Andersen, M. A., Patillo, P. D., Bishlawl, M., \& Foged, N. (1989). Rock compressibility, compaction, and subsidence in a high-porosity chalk Reservoir: A case study of Valhall Field. Journal of Petroleum Technology, 41(7), 210-223. https://doi.org/10.2523/18857-ms

Schroeder, C., Bois, A.-P., Maury, V., \& Halle, G. (1998). Water/Chalk (or Collapsible Soil) Interaction: Part II. Results of Tests Performed In Laboratory On Lixhe Chalk to Calibrate Water/Chalk Models. SPE, 505514. https://doi.org/10.2118/47587-ms

Schutjens, P. M. T. M., Kokker, P., Rai, U. B. B., Kandpal, J., Cid Alfaro, M. V., Hummel, N. D., et al. (2018). Compaction- and shear-induced well deformation in Tyra : Geomechanics for impact on production. In 52nd US Rock Mechanics / Geomechanics Symposium. Seattle: ARMA.

da Silva, F., Monjoie, A., Debande, G., Schroeder, C., Poot, B., Detiege, C., \& Halleux, L. (1985). Mechanical Behaviour of Chalks. Stavanger, Norway: Second North Sea Chalk Symposium.

Smits, R. M. M., de Waal, J. A., \& van Kooten, J. F. C. (1988). Prediction of Abrupt Reservoir Compaction and Surface Subsidence Caused By Pore Collapse in Carbonates. SPE Formation Evaluation, 340-346. https://doi.org/10.2118/15642-pa

This article is protected by copyright. All rights reserved. 
Taibi, S., Duperret, A., \& Fleureau, J. M. (2009). The effect of suction on the hydro-mechanical behaviour of chalk rocks. Engineering Geology, 106, 40-50. https://doi.org/10.1016/j.enggeo.2009.02.012

Talesnick, M., \& Shehadeh, S. (2007). The effect of water content on the mechanical response of a highporosity chalk. International Journal of Rock Mechanics and Mining Sciences, 44, 584-600. https://doi.org/10.1016/j.ijrmms.2006.07.016

Teufel, L. W., Rhett, D. W., \& Farrell, H. E. (1991). Effect of reservoir depletion and pore pressure drawdown on in situ stress and deformation in the Ekofisk Field, North sea. (Roegiers, Ed.), Proceedings of SPE 66th annual technical comference \& exhibition. Dallas.

Vajdova, V., Baud, P., Wu, L., \& Wong, T.-F. (2012). Micromechanics of inelastic compaction in two allochemical limestones. Journal of Structural Geology, 43, 100-117.

https://doi.org/10.1016/j.jsg.2012.07.006

Vejbæk, O. V., Mohamed, F. R., \& Herwanger, J. V. (2014). 4D seismic, 4D geomechanics and hydraulic stimulation in the low permeability South Arne chalk field. First Break, 32(6), 139-148.

de Waal, J. A. (1986). On the Rate Type Compaction Behaviour of Sandstone Reservoir Rock (Doctoral dissertation). Technische Universiteit Delft, Delft, NL.

Xie, S. Y., \& Shao, J. F. (2006). Elastoplastic deformation of a porous rock and water interaction. International Journal of Plasticity, 22, 2195-2225. https://doi.org/10.1016/j.ijplas.2006.03.002

Zhang, X., \& Spiers, C. J. (2005). Compaction of granular calcite by pressure solution at room temperature and effects of pore fluid chemistry. International Journal of Rock Mechanics and Mining Sciences, 42, 950960. https://doi.org/10.1016/j.ijrmms.2005.05.017

This article is protected by copyright. All rights reserved. 


\section{Figure caption}

Figure 1. Schematic $p_{m}^{\prime}-q$ plot showing the yield surface that consists of the shear failure line (Sh. Failure) and the end cap. Idealised stress paths for the hydrostatic compaction (bold grey line), uniaxial strain compaction (grey line) and shear failure tests (dashed grey line) are displayed. Note that shear failure tests characterise both the shear failure line and end cap depending on the chosen stress path. $S_{0}=$ rock cohesion, $\varphi=$ the friction angle, $T_{0}=$ tensile strength, $\sigma_{\text {hy }}=$ hydrostatic yield stress.

Figure 2. Four examples of the stress-strain evolution during hydrostatic compaction (a), uniaxial strain compaction (b, d) and shear failure tests (c) (samples 16, 20, 31 and 36). The elastic to elasto-plastic transition is characterised by the initial, representative and final yield stresses as shown for samples 31 and 20. Note that a fitting stress-strain curve is extrapolated between data points prior to the calculation. Note also the change in stress conditions from hydrostatic loading (light grey) to constant radial stress at $18 \mathrm{MPa}$ with increasing the axial stress up to $50 \mathrm{MPa}$ (dark grey) during the testing of sample 36 (c). The test procedures and sample properties are listed in Table 1.

Figure 3. Mean amount of quartz and associated standard deviation of the tested reservoir chalk samples per porosity class. Note the overall increase in the quartz content with decreasing porosity.

Figure 4. The $\mathrm{p}_{\mathrm{m}}^{\prime}$-q plots showing the stress conditions at shear failure (black circles) and the $\sigma_{\mathrm{y}, \text { in. }}$ (green), $\sigma_{\mathrm{y}, \text { rep. }}$ (black) and $\sigma_{\mathrm{y} \text {,fin. }}$ (red) for the triaxial tests carried out on fully oil-saturated Maastrichtian chalk specimens. For each porosity class, i) the values of $\sigma_{y}$ measured during the same test are linked by a solid black line, ii) each type of $\sigma_{\mathrm{y}}$ (initial, representative and final) is connected by a straight dashed line (grey) to visualise the end cap and iii) a linear fitting curve represents the shear failure line at low confining stress (dashed black line). The two half axes $(a, b)$ are used to estimate the aspect ratio of elliptical end caps. Note that, for the 35-37.5\% porosity class, an average value of $p_{m}^{\prime}$ is used to calculate the half axis a because the maximum value of $q$ is observed in two points. Note also the change of scale of the axes among the graphs.

Figure 5. Correlations between porosity $(\Phi)$ and the $\sigma_{\text {hy }}$ of oil-saturated chalk specimens (a), friction angle $\varphi$ (b) and rock cohesion $S_{0}$ (c) based on experimental data shown in Figure 4. The mean $\sigma_{\text {hy,in. }}\left(\right.$ green), $\sigma_{\text {hy,rep. }}$ (black) and $\sigma_{\text {hy,fin. }}($ red) are calculated per porosity class (a). Porosity is in fraction in the fitting functions.

Figure 6. Correlation between porosity and the parameter к (Eq. 3). Two linear fitting functions are shown with porosity in fraction. The first function (solid line) considers the minimum value of к per porosity class (triangle) and the second one (dashed line) includes all the data points. The first fitted curve is considered for calculation in order to estimate the maximum impact of the water weakening effect on chalk strength.

Figure 7. The $\mathrm{p}_{\mathrm{m}}^{\prime}$-q plots showing the initial (green line) and final (red line) yield surfaces reconstructed using the yield function (Eq. 1). The experimental data on shear failure (circle) and pore collapse (dot) are also displayed. Note the change in the curvature of the end cap below and above $c a$. $40 \%$ porosity as observed in the experimental dataset shown in Figure 4. Note also the change of scale of the axes among the graphs.

This article is protected by copyright. All rights reserved. 
Figure 8. Correlations between porosity and the m parameter (Eq. 6) for oil-saturated Maastrichtian chalk. A stepwise function is here chosen and the curve fitting uses the L2 norm for error minimisation. The $m$ parameter values corresponding to the initial (dots) and final (circle) yield surface are displayed.

Figure 9. The yield surfaces of oil-saturated (left hand side) and water-saturated (right hand side) Maastrichtian reservoir chalk in $\mathrm{p}_{\mathrm{m}}^{\prime}$-q-porosity plots (top) and $\mathrm{p}_{\mathrm{m}}^{\prime}-\mathrm{q}$ plots (bottom). The color bar (bottom right) corresponds to the deviatoric stress values. Note the shrinkage of the yield surface, i.e. the softening of chalk specimens from oil- to water-saturated conditions. Thick solid lines separate the porosity classes on the yield surfaces.

Figure 10. $p_{\mathrm{m}}^{\prime}-\mathrm{q}$ plots showing the impact of change in $S_{\mathrm{w}}$ on the yield surface of chalk for four different porosity values. Note that the impact of the water weakening effect on rock strength reduces as porosity decreases.

This article is protected by copyright. All rights reserved. 


\section{Table caption}

Table 1. List of the test procedures and specimen properties for the laboratory experiments carried out on fully oil-saturated chalk. The file number (nb.) refers to the file name containing the stress-strain data used in this study and accessible upon registration from http://jointchalkresearch.org/. Note that the radial stress applied during shear tests is in brackets. $\mathrm{H} / \mathrm{D}$ ratio = height/diameter ratio, $\Phi=$ porosity, clean. = cleaning procedure, $\mathrm{CF}=$ cold flush, $\sigma_{\mathrm{a}}=$ axial stress, Hydr. Cell $=$ hydrostatic cell, Tr. Cell $=$ triaxial test, $\mathrm{Pp}=$ pore pressure, Unk. = unknown, $\mathrm{T}=$ temperature, $\dot{\varepsilon}=$ strain rate, $\mathrm{H}$-comp $=$ hydrostatic compaction test, U-comp = uniaxial compaction test. The oil phase is either crude oil (1), isopar-L (2), soltrol (3), Exxol-D60 (4) or white oil (5).

Table 2. Compilation of the experimental data from hydrostatic compaction tests carried out on oil-saturated chalk. Details on the experimental procedure for each sample label are listed in Table 1.

Table 3. Compilation of the 12 test results on the $\sigma_{\text {hy }}$ of $20 \%$ and $100 \%$ water-saturated specimens. The average values $\sigma_{\text {hy,rep. }}\left(S_{\mathrm{w}}=0\right)$ per porosity class used to estimate the ratio $\mathrm{K}$ (Eqs 2, 3) are estimated from Table 2.

Table 4. Compilation of hydrostatic test results carried out on fully oil- and water-saturated outcrop chalk specimens associated with the applied strain and stress rate. The parameter $\kappa$ (Eq. 2) is calculated for each experiment. Note that the water weakening effect appears relatively constant across the $34 \%$ to $44 \%$ porosity range reducing by $c a$. $50 \%$ rock strength.

This article is protected by copyright. All rights reserved. 


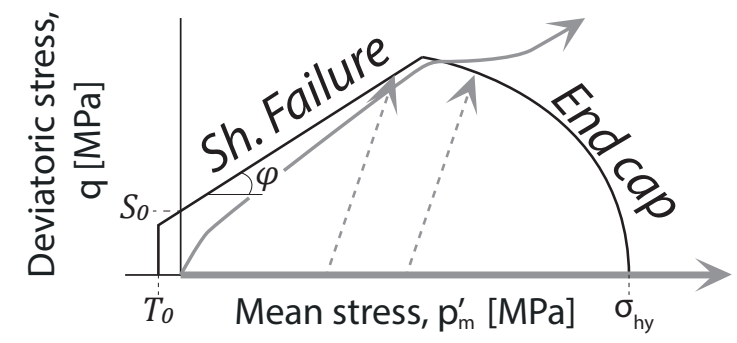

This article is protected by copyright. All rights reserved. 


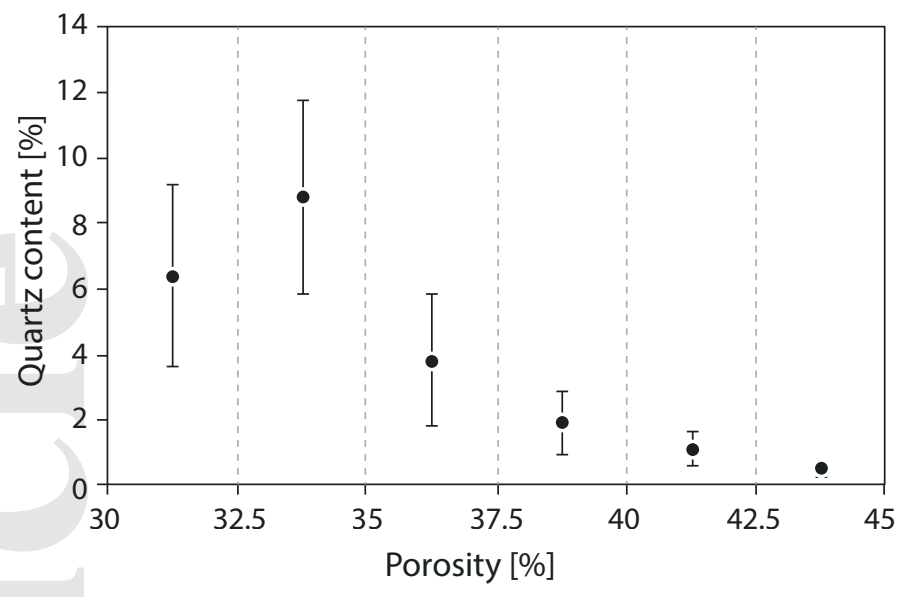

This article is protected by copyright. All rights reserved. 

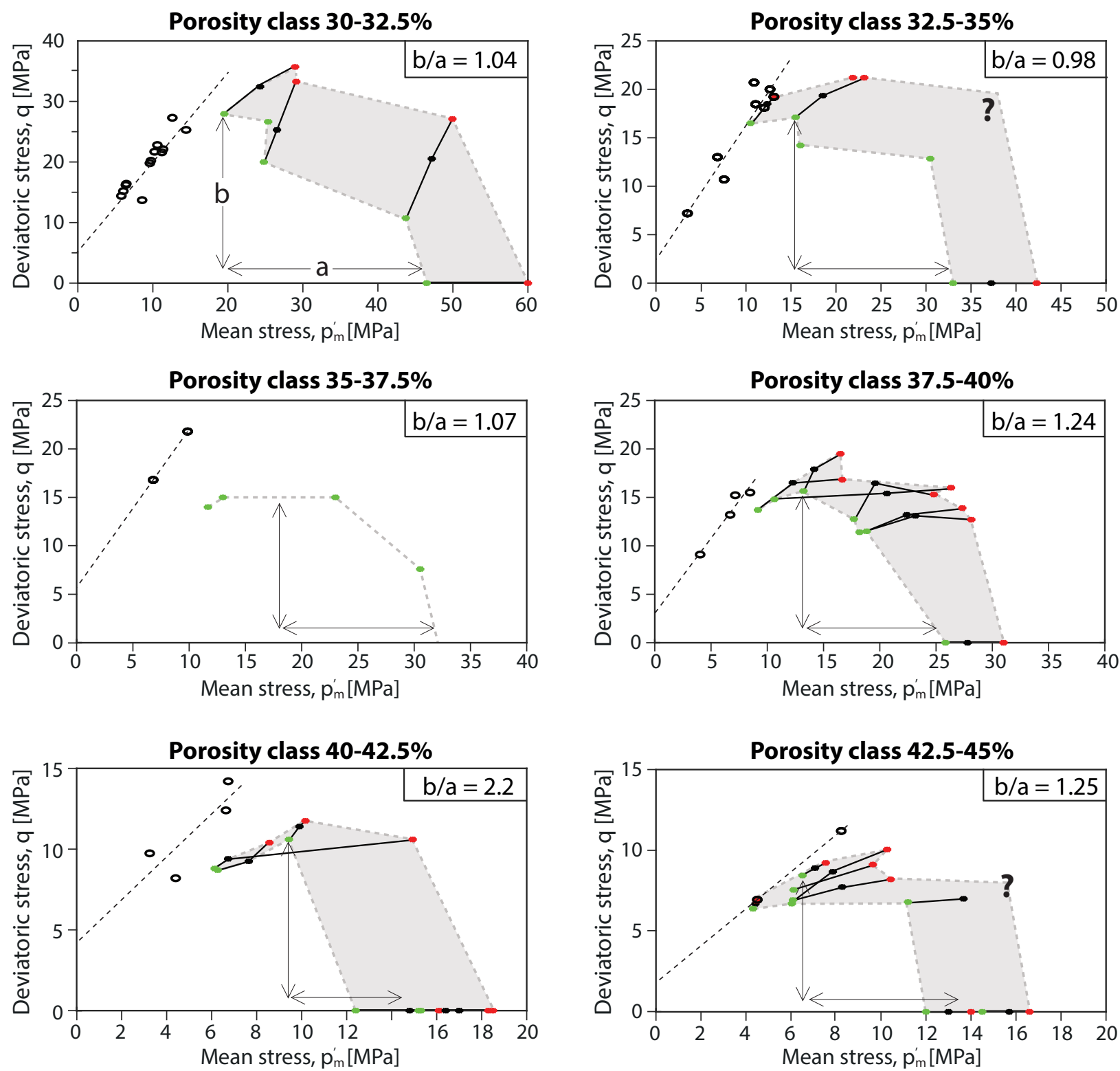

This article is protected by copyright. All rights reserved. 

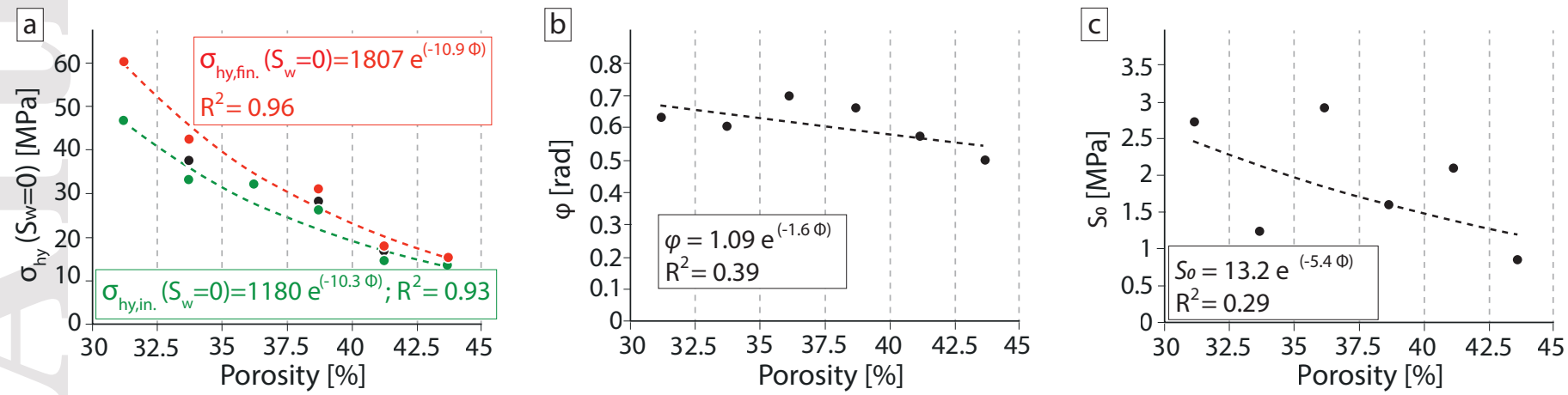

This article is protected by copyright. All rights reserved. 


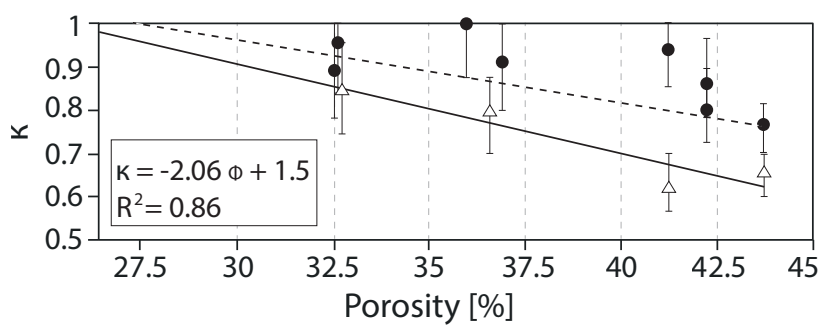

This article is protected by copyright. All rights reserved. 

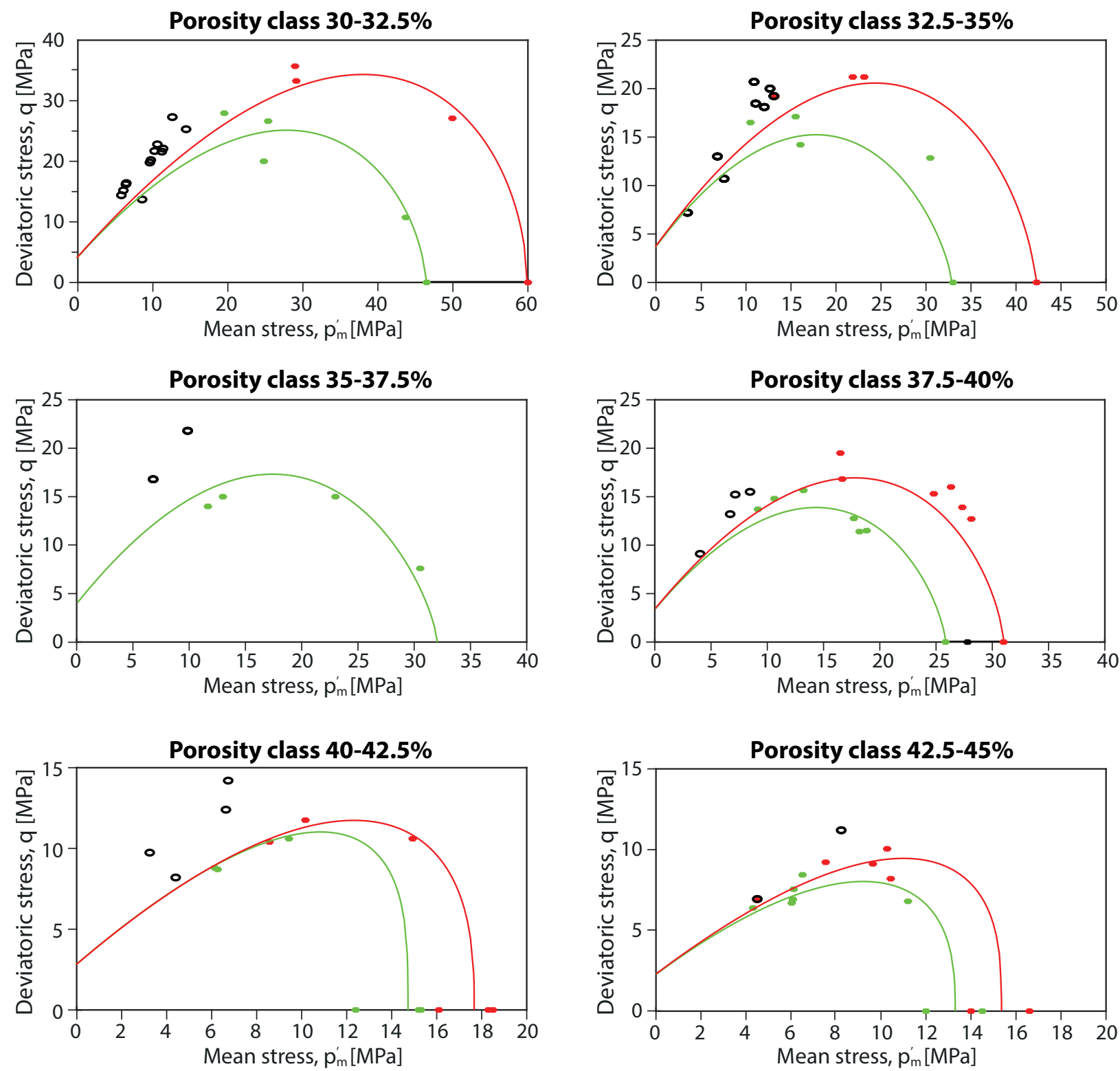

This article is protected by copyright. All rights reserved. 


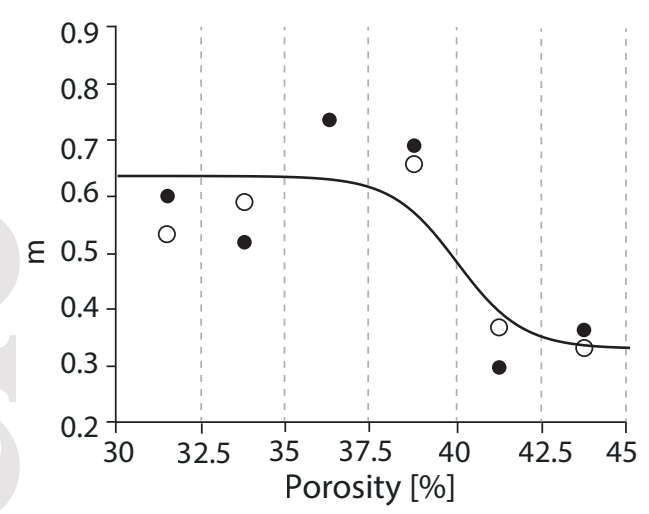

This article is protected by copyright. All rights reserved. 

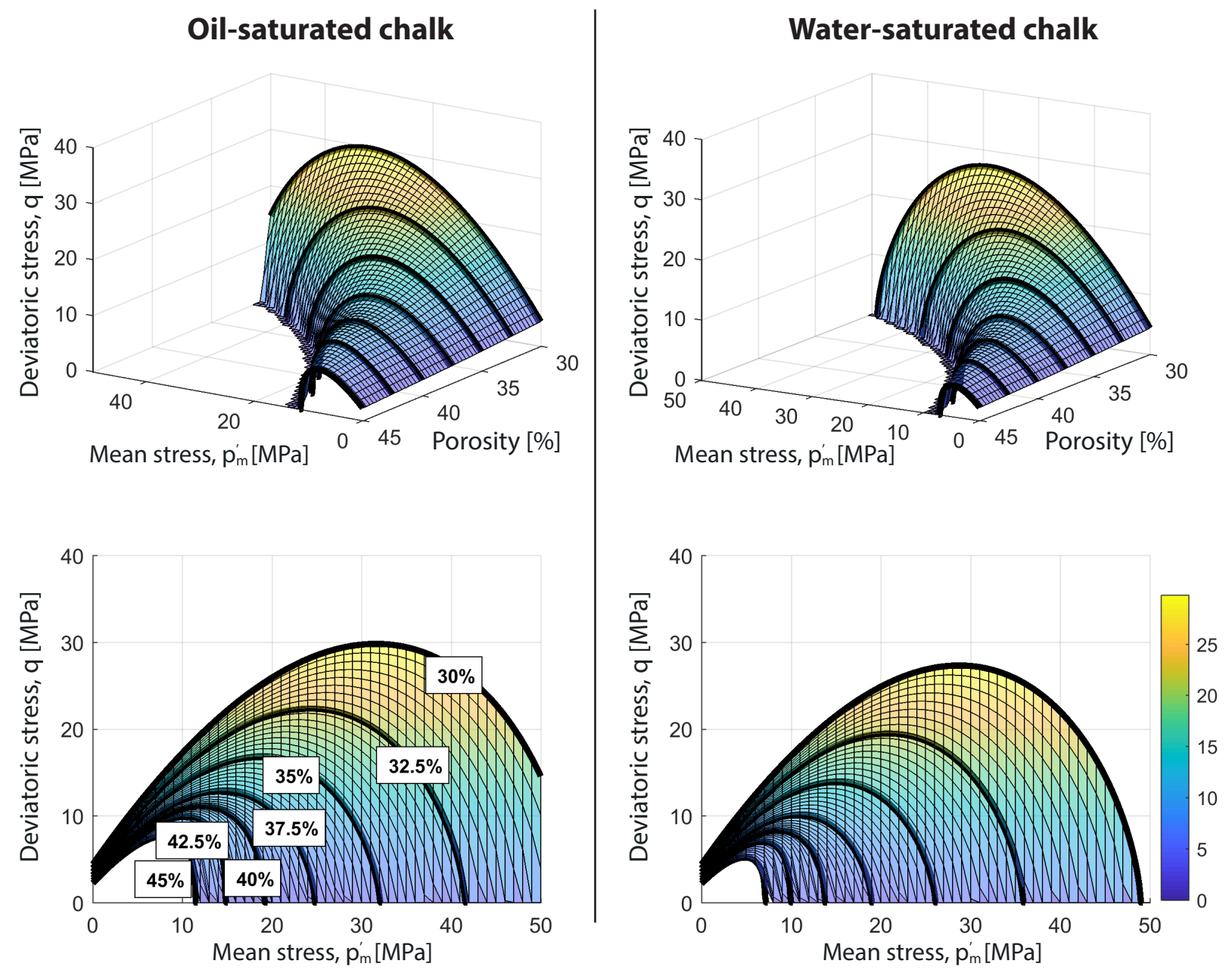

This article is protected by copyright. All rights reserved. 

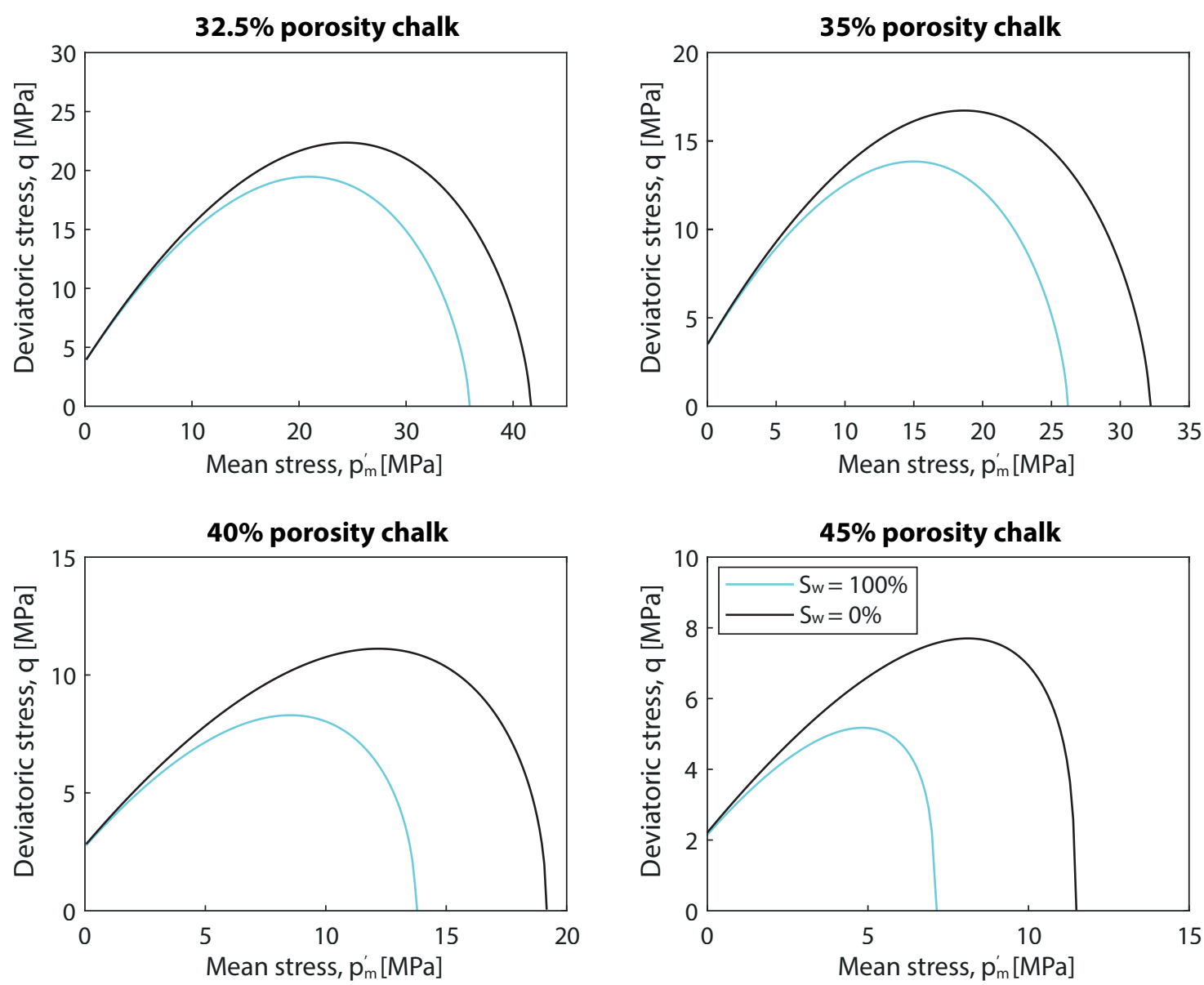

This article is protected by copyright. All rights reserved. 